medRxiv preprint doi: https://doi.org/10.1101/2021.05.12.21256925; this version posted May 13, 2021. The copyright holder for this preprint (which was not certified by peer review) is the author/funder, who has granted medRxiv a license to display the preprint in perpetuity. It is made available under a CC-BY-NC-ND 4.0 International license .

\title{
Neocortical Localization and Thalamocortical Modulation of Neuronal Hyperexcitability in Fragile $X$ Syndrome
}

Authors: Ernest V Pedapati ${ }^{1,2,3^{*}}$, Lauren M. Schmitt ${ }^{4,8}$, Rui Liu ${ }^{1}$, Lauren E. Ethridge ${ }^{5,6}$, Elizabeth Smith $^{7,8}$, John A Sweeney ${ }^{3}$, Rebecca C. Shaffer ${ }^{4,8}$, Kelli C. Dominick ${ }^{1,3}$, Donald L. Gilbert ${ }^{2,8}$, Steve W. Wu ${ }^{2,8}$, Paul S. Horn ${ }^{2}$, Devin Binder ${ }^{9}$, Martine Lamy ${ }^{1,3}$, Megan Axford ${ }^{1}$, Makoto Miyakoshi $^{10}$, and Craig A. Erickson ${ }^{1,3}$

\section{Affiliations:}

${ }^{1}$ Division of Child and Adolescent Psychiatry, Cincinnati Children's Hospital Medical Center, Cincinnati, $\mathrm{OH}$, United States.

2Division of Neurology, Cincinnati Children's Hospital Medical Center, Cincinnati, OH, United States.

${ }^{3}$ Department of Psychiatry, University of Cincinnati College of Medicine, Cincinnati, OH, United States

${ }^{4}$ Division of Developmental and Behavioral Pediatrics, Cincinnati Children's Hospital Medical Center, Cincinnati, $\mathrm{OH}$, United States

${ }^{5}$ Department of Pediatrics, Section on Developmental and Behavioral Pediatrics, University of Oklahoma Health Sciences Center, Oklahoma City, OK

${ }^{6}$ Department of Psychology, University of Oklahoma, Norman, OK

${ }^{7}$ Division of Behavioral Medicine and Clinical Psychology, Cincinnati Children's Hospital Medical Center, Cincinnati, $\mathrm{OH}$, United States

${ }^{8}$ Department of Pediatrics, University of Cincinnati College of Medicine, Cincinnati, $\mathrm{OH}$, United States

${ }^{9}$ Division of Biomedical Sciences, School of Medicine, University of California, Riverside.

${ }^{10}$ Swartz Center for Neural Computation, Institute for Neural Computation, University of California, San Diego, San Diego, CA, United States

* Corresponding author: Ernest Pedapati, ernest.pedapati@cchmc.org

Division of Child and Adolescent Psychiatry, Division of Neurology, Cincinnati Children's Hospital Medical Center, 3333 Burnet Ave, MLC 4002, Cincinnati, OH 45229

Keywords: Fragile X Syndrome, Translational medicine, Thalamocortical, Electroencephalography, Gamma Oscillations, Neurodevelopmental Disorders

Author contributions: Conceptualization: E.V.P., J.A.S, C.A.E, and D.B., Data collection: M.A., R.C.S., C.A.E, E.V.P., K.C.D, and C.A.E., Writing (original draft): E.V.P., R.L., J.A.S., L.M.S., Writing (review and editing): E.S., R.C.S, M.M., M.L, D.L.G., and S.W., Data curation: M.A., R.L., and E.V.P, Analysis and Statistics: R.L., P.S.H, and E.V.P., and Supervision: J.A.S., C.A.E. Competing interests: The authors have indicated no conflicts interest with the present data. Data and materials availability: EEG data is available to the public as federally mandated 
at the National Database for Autism Research (NDAR). Analysis code is in preparation for upload into public repositories and is available on request.

Acknowledgments: We thank the participants and families who participated in this study. We would also like to thank Nicole Friedman, Michael Hong, Danielle Chin, and Janna Guilfoyle who assisted with project. The present study was federally funded by National Institutes of Health (NIH) Fragile X Center (U54HD082008). 
Title: Neocortical Localization and Thalamocortical Modulation of Neuronal Hyperexcitability in Fragile X Syndrome
Abstract:
Fragile $X$ Syndrome (FXS) is a monogenetic form of intellectual disability and autism in which well-established knockout (KO) animal models point to neuronal hyperexcitability and abnormal gamma-frequency physiology as a basis for key illness features. Translating these findings into patients may identify tractable treatment targets. Using a minimum norm estimate of resting state electroencephalography data, we report novel findings in FXS including: 1) increases in gamma activity across functional networks, 2) pervasive changes of theta/alpha activity, indicative of disrupted thalamocortical modulation coupled with elevated gamma power, 3) stepwise moderation of these abnormalities based on female sex and genetic mosaicism, and 4) relationship of this physiology to intellectual disability and anxiety. Our observations extend findings in $\mathrm{Fmr1}^{-1-} \mathrm{KO}$ mice to patients with $\mathrm{FXS}$ and raise a key role for disrupted thalamocortical modulation in local hyperexcitability, a mechanism that has received limited preclinical attention, but has significant implications for understanding fundamental disease mechanisms. 
medRxiv preprint doi: https://doi.org/10.1101/2021.05.12.21256925; this version posted May 13, 2021. The copyright holder for this preprint (which was not certified by peer review) is the author/funder, who has granted medRxiv a license to display the preprint in perpetuity. It is made available under a CC-BY-NC-ND 4.0 International license .

\section{Introduction}

During spontaneous brain recordings, measured fluctuations in neural activity reveal highly structured functional dynamics in resting-state networks (RSN) ${ }^{1}$ that can be characterized with millisecond resolution using dense-array electroencephalography ${ }^{2}$. In neurodevelopmental disorders (NDDs), higher order cognition, emotional regulation, and sensorimotor functions are notably altered ${ }^{3}$. However, the cortical activity that engender these changes remain largely unknown. In monogenetic NDDs, where animal models are well established, slice and unit electrophysiology studies of $F m r^{-/-}$knockout mice $(\mathrm{KO})$ have led to interest in in vivo dense array electroencephalography (EEG), paralleling similar interest of neural dysfunction in clinical research. Thus, translational electrophysiological investigations now provide a novel strategy for developing targets for clinical intervention and trans-species biomarkers for predicting and tracking drug effects ${ }^{4}$.

Fragile $X$ Syndrome (FXS) is a promising target as clinical and preclinical research suggests neural hyperexcitability as a key illness feature ${ }^{5,6}$. FXS involves reduced production of fragile $X$ mental retardation protein (FMRP) that is encoded by FMR1 on the X chromosome. FMRP is an RNA binding protein that regulates protein synthesis at synapses, maintains synaptic plasticity, and is crucial for higher order cognitive functions ${ }^{7}$. Reduced levels of FMRP result in near universal intellectual disability with a high prevalence of anxiety disorders, communication impairments, sensory hypersensitivities, and autism. Fmr $1^{-1-} \mathrm{KO}$ display evidence of heightened cortical excitability and altered excitatory/inhibitory (E-I) homeostatic mechanisms ${ }^{8,9}$. For example, $\mathrm{Fmr1}^{-/-} \mathrm{KO}$ have increased susceptibility to audiogenic seizures and enhanced gamma oscillatory activity $(>30 \mathrm{~Hz})$ as measured by murine multielectrode array ${ }^{10-12}$. Microcircuit experiments in $\mathrm{Fmr}^{-1-} \mathrm{KO}$ cortical slices have established excessive spontaneous network spiking, enhanced gamma power, and altered gamma synchrony between cortical L2/3 and L4 cortical layers ${ }^{8,13}$

EEG from $\mathrm{Fmr1}^{-/-} \mathrm{KO}$ and patients with FXS have increased spontaneous, broadband gamma power and diminished narrow-band gamma response to auditory stimuli ${ }^{11}$. These preliminary investigations also indicate that excess intrinsic gamma activity is associated with electrophysiological alterations during sensory evoked ${ }^{14}$ and speech production tasks ${ }^{15}$. However, human EEG studies of FXS have been limited by small samples $(n<25)$, under representation of females, failure to ascertain mosaic status in males, and lack of source and functional network modeling ${ }^{16}$. Gamma oscillations hold special interest for NDDs because of their relation to cortical excitability and cognition ${ }^{17}$. While studies of gamma power face challenges using scalp recordings, the reconstruction of source activations from scalp EEG signals in concert with independent component analysis (ICA) can effectively improve spatiotemporal resolution by reducing volume conduction effects and contamination of highfrequency activity by scalp musculature ${ }^{18}$.

Here, in a relatively large sample of FXS patients, we report on neural activity at the cortical source level and the relationships of this activity with disease features. We demonstrate regional and network-based broadband gamma elevations related to severity of intellectual disability and neuropsychiatric symptoms. We also demonstrate a marked attenuation of alpha activity (with a concomitant increase in theta activity) and altered coherence of this low-frequency activity with gamma activity, which is highly suggestive of disruptions of thalamocortical modulation of 
medRxiv preprint doi: https://doi.org/10.1101/2021.05.12.21256925; this version posted May 13, 2021. The copyright holder for this preprint (which was not certified by peer review) is the author/funder, who has granted medRxiv a license to display the preprint in perpetuity. It is made available under a CC-BY-NC-ND 4.0 International license .

neocortical hyperexcitability. Comparisons of full-mutation male and female FXS participants (obligate mosaics) indicated that modest FMRP expression in females appear to mitigate excessive broadband gamma activity but certain alterations in thalamocortical function persist. The present findings provide a comprehensive profile of resting-state cortical activity in a monogenetic NDD that confirms and extends mechanistic gamma findings of the $\mathrm{FMR}^{-/-} \mathrm{KO}$ at the local circuit level, novel insights into low-frequency thalamocortical activity in influencing neocortical hyperexcitability, and strong evidence of the relation of these alterations to core clinical features of FXS.

\section{Results}

\section{Source-estimation reveals broadband spectral alterations}

Eighty-seconds of artifact-free data were analysed for each participant based on blinded, semiautonomous pre-processing (see Methods and Figure 1a) from five-minutes of continuous EEG recording from 141 study participants: 70 individuals with a genetic diagnosis of FXS (without seizures or on antiepileptics) and 71 age- and sex-matched typically developing control participants (see Table 1 and Table S1). Non-verbal intelligence quotients (NVIQ) were severely reduced in males with $\mathrm{FXS}(\mathrm{M}=22.1,95 \% \mathrm{Cl}$ [12-32.2]) and to a lesser degree in females ( $M=59.2,95 \% \mathrm{Cl}$ [47.1-71.3]; see Figure 1b).

Comparisons of topographic relative power from scalp EEG (see Figure S1) and peak alpha frequency (see Figure 1c) are suggestive of cortical hyperexcitability (high broadband gamma) and reduced long-range modulation (reduced alpha peak frequency) in FXS. The source distributions of these alterations have remained ambiguous. To estimate the distribution of neural currents, we constructed a depth-weighted minimum norm estimate (MNE) model in Brainstorm ${ }^{19}$. Scalp electrodes were co-registered to an averaged Montreal Neurologic Institute (MNI) ICBM152 common brain template (see Figure 1a). Current source density (CSD) was computed across a resultant triangular mesh (15,002 vertices) which represented the cortical envelope. The Desikan-Killiany (DK) atlas ${ }^{20}$ was used to parcellate vertices into 68 cortical nodes (see Table S14).

Vertex-level comparison of FXS and control groups (see Figure 1d) indicated that FXS participants demonstrated widespread cortical elevation of delta $(2-3.5 \mathrm{~Hz})$, theta $(4-7.5 \mathrm{~Hz})$, gamma1 $(30-55 \mathrm{~Hz})$, and gamma2 $(65-90 \mathrm{~Hz})$ activity. Significant increases in gamma activity were noted across bilateral temporal lobes with limited involvement of bilateral parietal and occipital lobes. Alpha1 $(8-10 \mathrm{~Hz})$ and alpha2 $(10.5-12.5 \mathrm{~Hz})$ activity was decreased bilaterally throughout the neocortex, with relative sparing noted in frontal cortex. Beta $(13-30 \mathrm{~Hz})$ activity was attenuated across frontal and posterior regions, with elevated activity in $\mathrm{R}$ temporal lobe.

Clinical Correlations: In FXS, age-adjusted correlations were identified between gamma1 power and NVIQ (rho = -.27, $p<.05, \mathrm{n}=64$ ), and alpha2 power and social communication (rho $=.33$, $p<.01, \mathrm{n}=62$ ), obsessive compulsive symptoms ( $\mathrm{rho}=-.43, p<.001, \mathrm{n}=64)$, irritability $(\mathrm{rho}=-.28$, $p<.05, \mathrm{n}=61)$, and hyperactivity ( $\mathrm{rho}=-.30, p<.05, \mathrm{n}=61$ ) (see Table S2).

\section{Group comparisons of cortical parcellation maps}

Next, using a linear mixed effect model (LME) we identified group differences in log relative power at the atlas node level $\left(F_{402,66025}=1.14, p=.03\right.$; see Methods). Corrected contrasts 
medRxiv preprint doi: https://doi.org/10.1101/2021.05.12.21256925; this version posted May 13, 2021. The copyright holder for this preprint (which was not certified by peer review) is the author/funder, who has granted medRxiv a license to display the preprint in perpetuity. It is made available under a CC-BY-NC-ND 4.0 International license .

between groups were tabulated including centroid coordinates and statistical significance (see Table S3) and top significant contrasts summarized in Table 2.

Within the theta band, 29/68 nodes survived correction with the largest increases in FXS compared to controls being found within bilateral paracentral and posterior cingulate regions, and in right $(R)$ precuneus. For the alpha1 band, temporal regions had reduced power in FXS including the bilateral temporal pole and entorhinal cortex. Alpha2 power was globally reduced (all 68 nodes) in FXS with the largest reduction seen in the bilateral paracentral and posterior cingulate regions. Fifteen out of 68 nodes demonstrated a reduction within the beta band in FXS including five nodes in across the prefrontal cortex region. Gamma1 (15/68 significant nodes) and gamma2 (13/68 significant nodes) power was increased in FXS. The most robust elevations were seen in bilateral superior temporal sulcus and transverse temporal gyri, and $R$ isthmus of the cingulate gyrus.

\section{Evidence for thalamocortical abnormalities in FXS}

Cortical alpha rhythms in neocortex are primarily generated by thalamic input with some contributions from other neocortical sources. A constellation of findings known as thalamocortical dysrhythmia (TCD) has been observed in states such as epilepsy, tinnitus, and severe neuropsychiatric disease and supported by direct recordings from human thalamus and animal models ${ }^{21,22}$. EEG evidence of suggestive of TCD is present in FXS including consists of 1) leftward shift of peak alpha frequency towards the theta frequency, 2) centralized distribution (known as anteriorization) of "slow" alpha frequencies, 3) increased spontaneous gamma activity, and 4) inversion of gamma to theta and alpha power coupling relationships. Reduced peak frequency in FXS: Similar to scalp EEG, the average alpha peak frequency computed from DMN nodes was reduced in in FXS (see Figure 2a; FXS males, $M=7.7 \mathrm{~Hz}, S D=.88$; FXS females, $M=8.1 \mathrm{~Hz}, \mathrm{SD}=.96$ ) compared to control groups (Control males, $M=8.7, \mathrm{SD}=1.2 \mathrm{~Hz}$; Control females, $M=8.6, S D=1.3 \mathrm{~Hz} ; \mathrm{F}_{1,133}=16.5$, $\mathrm{p}<.001$ ).

\section{Predominance of Theta-Gamma coherence in FXS}

Cross-frequency coupling (CFC) examines the association between the magnitude of the recorded signal over time and between frequency bands ${ }^{23}$. Higher coherence between theta and gamma scalp EEG activity compared to alpha-gamma activity has been detected in FXS, while the reverse was seen in control participants ${ }^{24}$. This inversion has been associated with disruptions in task-related functional activity and cognitive processing ${ }^{25}$. We assessed mean CFC (expressed in normalized Fisher's Z-based correlation coefficients) between all pairwise nodes within the DMN network. A significant inversion of alpha/theta AAC relationships $\left(F_{1,4172}=7.6, p<.01\right)$ favouring theta-gamma over alpha-gamma coupling was found in $F X S$ (see Figure 2b).

\section{"Anteriorized" Distribution of Alpha Slowing in FXS}

To further clarify the distribution of the "slowed" alpha power, we calculated alpha-shift as the ratio of alpha1 to alpha2 relative power, with a higher ratio indicating greater alpha1 compared to higher alpha2 ${ }^{26}$ (see Table S5). We observed a significant third order interaction effect $\left(F_{3,4359}=17.6, p<2.5 \times 10^{-11}\right.$; no effect of age $\left.F_{1,136}=.84, p=.35\right)$ indicating that males with $F X S$ had a greater alpha shift in central nodes compared to occipital, parietal, or frontal nodes (Cohen's $\mathrm{d}=.3-.7$; see Figure 2c-d and Table S6,7). 
medRxiv preprint doi: https://doi.org/10.1101/2021.05.12.21256925; this version posted May 13, 2021. The copyright holder for this preprint (which was not certified by peer review) is the author/funder, who has granted medRxiv a license to display the preprint in perpetuity. It is made available under a CC-BY-NC-ND 4.0 International license .

\section{Oscillatory activity in cognitive and affective networks}

Small sample functional magnetic resonance imaging (fMRI) studies have demonstrated reduced connectivity across brain networks in $\mathrm{FXS}^{27}$. Dynamic EEG RSNs defined by connectivity analysis and within EEG source space allows for study at much higher temporal resolution, allowing higher frequencies of brain activity not accessible by $\mathrm{FMRI}^{28}$. We reconstructed five RSNs: default mode network (DMN), default attention network (DAN), salience affective network (SAN), visual network (VIS), and the auditory network (AUD; see Supplement Table 13). Prominent group differences (FXS-Control) in RSN activity by frequency band emerged at the node level in $\operatorname{DMN}\left(F_{24,43151}=3.06, p<1 \times 10^{-4}\right)$ and in other networks. Bar plots summarizing RSN comparisons in males with FXS (with control males and affected females) are found Figure 3b. Between and within group comparisons of females with FXS and female controls are in Figure S5). Age-adjusted, FDR-corrected clinical correlations were calculated based on mean RSN and node level activity for low (theta, alpha1, and alpha2) and high frequency bands (beta, gamma1, and gamma2).

\section{Cognitive Networks (see Figure 3a for DMN and Figure S3 for DAN and SAN networks)}

Default Mode Network (DMN): Functional and structural alterations of DMN have been associated with intellectual deficits in $\mathrm{FXS}^{27}$. Group differences: Theta band: elevated in 7 of 14 nodes in FXS including aspects of the cingulate cortex $(R$ anterior, $p<.05$, bilateral posterior, $p<.01$, bilateral isthmus (iCC), $p<.05$ ), and bilateral precuneus, $p<.05$. Alpha: Alpha1 was decreased in 11 of 14 nodes $\left(p<1 \times 10^{-5}\right)$. Alpha2 was decreased across all 14 nodes, $p<1 \times 10^{-5}$. Gamma: Gamma1 elevated in 4 of 14 nodes (bilateral parahippocampus, $p<.05$, and bilateral isthmus of the cingulate cortex, $p<.05)$ and gamma2 elevated in 2 of 14 nodes $(R$ parahippocampus, $p<.05$, and $\mathrm{R}$ iCC, $\mathrm{p}<.05$ ).

Dorsal attention network (DAN): Attentional abilities are impaired and prognostic in FXS ${ }^{29}$. DAN regions are associated with top-down regulation of task activity or sensory processing. Group differences: Theta: Elevated in two out of 11 nodes in FXS ( $L$ pars opercularis, $p<.05$ and $L$ anterior cingulate, $p<.05)$. Alpha: Alpha1 power was reduced in $5 / 11$ nodes, $p<.001$, and alpha2 was reduced across all nodes, $\mathrm{p}<1 \times 10^{-5}$. Gamma: Gamma1 and gamma2 power was similarly elevated in 2 of 11 nodes $(p<.05)$ including $L$ middle and inferior temporal gyrus.

Salience Affective Network (SAN): Regions within the SAN are involved in the integration of sensory, emotional, and cognitive information including interoception and subjective awareness 30. Theta: Elevated in 5 of 8 nodes in FXS ( $L$ insula, $p<.05$, bilateral supramarginal gyrus (SMAR), $p<.05$, and bilateral middle frontal gyrus, $p<.05)$. Alpha: Alpha1 power is decreased in 3 of 8 nodes (bilateral insula, $p<.05$, and R SMAR, $p<.05$ ) and alpha2 power was significantly decreased across all nodes $(p<.001)$. Gamma: Two out of 11 nodes had elevation of gamma power in FXS including the bilateral SMAR (gamma1: bilateral, $p<.01$; gamma2: R only, $p<.01$ ).

\section{Clinical correlations of cognitive networks}

Average DMN gamma1 power was inversely correlated with NVIQ in all FXS participants (rho=$.32, p=.01, \mathrm{n}=64)$ primarily in full mutation, non-mosaic males $(\mathrm{FM})(\mathrm{rho}=-.47, p=.028, \mathrm{n}=22)$, but not in affected males with mosaicism (MM) (rho=- .0091, $p=.99, \mathrm{n}=11$ ) or affected full mutation females (FF) (rho=-.15, $p=.41, \mathrm{n}=31$ ) (see Figure 3c). Significant node-by-node correlations of DMN, DAN, and SAN RSNs are presented in Supplemental Tables 9-11. In the 
medRxiv preprint doi: https://doi.org/10.1101/2021.05.12.21256925; this version posted May 13, 2021. The copyright holder for this preprint (which was not certified by peer review) is the author/funder, who has granted medRxiv a license to display the preprint in perpetuity. It is made available under a CC-BY-NC-ND 4.0 International license .

FM group, gamma1 power of the $L$ parahippocampus (DMN) had the strongest correlation with $\mathrm{NVIQ}$ (rho=-.63, $\mathrm{p}=.002$ ). Severity of anxiety and obsessive-compulsive symptoms across all FXS subjects and FM were significantly inversely associated with alpha1 and alpha2 power including in the orbitofrontal gyrus, bilateral parahippocampus, and temporal regions.

Sensory Networks (see Figure S3).

Consistent with polymodal sensory abnormalities in FXS, slice preparations from the auditory and visual cortices in $F m r 1^{-1-} \mathrm{KO}$ demonstrate immature dendritic spines, reduced synaptic pruning, circuit level hyperexcitability and altered neural synchrony ${ }^{31}$.

Auditory (AUD): Group Differences: Theta: No difference. Alpha: Both AUD nodes including the $R$ and $L$ superior temporal gyrus (STG) demonstrated decreased alpha1, $p<.05$, and decreased alpha2 power (R STG, $p<.001$ and L STG, $p<.05$ ). Gamma: Increased gamma1 (L STG only, $\mathrm{p}<.05$ ) and gamma2 power (R STG, $\mathrm{p}<.05$ and L STG, $\mathrm{p}<.05$ ).

Visual (VIS): Group differences: Theta: Elevated in 2 out of 8 nodes (bilateral cuneus, $p<.05$ ) Alpha: Alpha1 was reduced similarly in 6 of 8 nodes, including bilateral fusiform, lateral occipital gyrus, and lingual gyrus, $p<.05$. Alpha2 was decreased in $8 / 8$ nodes. Gamma: gamma1 was elevated in the $\mathrm{R}$ fusiform only, $\mathrm{p}<.05$.

Clinical Correlations of sensory networks: Mean gamma1 power in AUD (ALL: rho=-.35, $p<.01$, $\mathrm{n}=64$; FM only: rho $=-.49, \mathrm{p}<.05, \mathrm{n}=22$ ) and VIS (ALL: rho=-.43, $\mathrm{p}<.001, \mathrm{n}=64$; FM only: rho=$.63, \mathrm{p}<.01, \mathrm{n}=22$ ) were inversely correlated with NVIQ. Mean alpha2 power in VIS but not AUD was inversely associated with ADAMS anxiety score in full mutation males (rho $=-.55, p<.01$, $n=27$; see Figure 3d). Corrected sensory RSN nodal clinical correlations are presented in Table S12 and 13. Multiple nodes within the VIS and AUD demonstrated beta and gamma power correlations with NVIQ across all FXS subjects and the FM subset. Alpha power of nodes within the visual, but not auditory RSN, was correlated with anxiety and OCD symptoms. In the FM group, the $L$ fusiform gyri demonstrated the strongest association with anxiety severity (rho=-.63, $\mathrm{p}<.05, \mathrm{n}=27$ ) and OCD symptoms (rho=-.59, $\mathrm{p}<.05, \mathrm{n}=27$ ).

Intermediate Electrophysiological Alterations in Females with FXS

We conducted an LME which compared log relative power of five cortical regions (see Table S14) by frequency band. A $4^{\text {th }}$-order interaction effect of sex $x$ group $x$ region $x$ frequency band was identified, $F_{24,66839}=3.94, p<1 \times 10^{-4}$ (see Figure S4 and Table S4). Compared to affected females, males with FXS had similar theta power changes but greater increases in gamma1 and gamma2 power across all cortical regions, as well as reduced alpha1 (frontal and temporal) and alpha2 (central, frontal, and temporal) activity (see Table 3). Thus, females with FXS had lower local hyperexcitability (gamma power) and more typical patterns of thalamocortical influence as indexed by alpha activity ${ }^{32}$. Sex Differences in RSNs: We further studied the effect of group and sex on RSN activity identifying a $4^{\text {th }}$-order interaction Group $x$ Sex $x$ RSN $x$ Frequency $\left(F_{24,43151}=3.06, p<1 \times 10^{-4}\right)$. Figure $3 b$ depicts differences between males with $F X S$ and females with FXS (for other group contrasts see Figure S5). Females with FXS had similar alpha2 levels in sensory RSNs, but had increased alpha2 power in the DMN, DAN, and SAN. Gamma1 and gamma2 power was elevated in all RSN in males with FXS compared to females with FXS. 
medRxiv preprint doi: https://doi.org/10.1101/2021.05.12.21256925; this version posted May 13, 2021. The copyright holder for this preprint (which was not certified by peer review) is the author/funder, who has granted medRxiv a license to display the preprint in perpetuity. It is made available under a CC-BY-NC-ND 4.0 International license .

\section{Discussion}

Despite achievement of significant advances in mechanistic understanding of monogenic NDDs in animal models, translation of findings to patient-oriented research and successful treatment development have lagged. Development of translational biomarkers is needed to bridge this divide and spur progress in drug development ${ }^{4}$. In the present study, using source estimation of dense EEG resting-state data and neural network modeling in FXS, in a sample much larger than previous studies, yielded three novel findings. First, we observed clinically associated increases in gamma activity from cortical sources that varied across functional networks. Next, in the first study including a significant number of females with FXS, we identified a pattern of similarities and areas of reduced abnormalities relative to males. Third, we observed marked disruptions of theta/alpha activity indicative of thalamocortical dysfunction, which was coupled with elevated gamma power. Some observations, such as excessive gamma activity confirm findings in $\mathrm{Fmr1}^{-1-} \mathrm{KO}$, but long-range coupling disturbances suggests an important role for altered thalamocortical modulation of local circuit excitability in the neocortex. This systemslevel feature has received limited attention in preclinical research and may be an important mechanism for neocortical hyperexcitability.

In the present study, after blinded pre-processing to minimize myogenic artifact, elevations in gamma power were evident across bilateral temporal lobes and portions of the parietal and occipital lobes relative to sex- and age-matched controls. Node-by-node comparisons identified increased relative gamma power within superior temporal sulcus, fusiform region, cingulate cortex, supramarginal gyrus, and parahippocampus in FXS. Elevated resting gamma activity may disrupt circuits by decreasing signal-to-noise ratio therefore information processing.

We additionally observed widespread alterations in spectral power across RSNs that are relevant to cognition and brain disorders. We primarily focused on the DMN as it displays the highest level of fractional occupancy during resting EEG and serves as a key transition between other task-active RSNs ${ }^{33}$. Within the DMN, elevated gamma power was observed in the parahippocampal and cingulate gyri. These regions are recognized as among the strongest "hubs" or connector nodes as determined by the highest number of connections and the degree of network collapse when the node is removed ${ }^{2,34}$. Interestingly, these regions also demonstrated the highest degree of correlation between elevated gamma power and intellectual disability within full mutation males.

Sensory networks are of particular interest, as these have been intensively studied in the Fmr1/$\mathrm{KO}$ mouse model. Auditory and visual network nodes in FXS males displayed elevated intrinsic broadband gamma power, consistent with findings in the mouse model. This could contribute to altered sensory processing, as seen in our prior observations of a reduced ability of FXS patients to mount a $40 \mathrm{~Hz}$ phase-locking response to auditory stimuli, which was related to excess background gamma power ${ }^{14}$. Additionally, we have found less intelligible speech related to increased broadband phasic gamma power immediately prior to talking in frontal language cortex in FXS patients ${ }^{15}$. These findings point to the functional significance of excessive phasic and intrinsic broadband high-frequency activity in FXS. In the visual cortex, narrow-band gamma oscillations support features processing such as size, contrast, and spatiotemporal aspects $^{35}$. Reduced FMRP expression has been associated with impairments in contrast sensitivity at low spatial/high temporal frequency and motion coherence, implicating disruption 
medRxiv preprint doi: https://doi.org/10.1101/2021.05.12.21256925; this version posted May 13, 2021. The copyright holder for this preprint (which was not certified by peer review) is the author/funder, who has granted medRxiv a license to display the preprint in perpetuity. It is made available under a CC-BY-NC-ND 4.0 International license .

of magnocellular (M) pathway ${ }^{36}$. Mechanistically, increases in broadband gamma in cortex coupled with reduced thalamocortical modulation (as discussed below) would be expected to increased variability of spike timing and reduced spatiotemporal selectivity in sensory cortices with adverse functional effects on sensory processing.

The translational nature of electrophysiological research allows preclinical studies to identify mechanisms of the identified pathologies that can become targets for intervention. Pyramidal cells generate broadband, persistent gamma activity ${ }^{37}$, but canonically, interneurons such as fast-spiking parvalbumin (PV) GABAergic cells, are critical to "sharpening" gamma oscillations to synchronize and shape population activity ${ }^{38}$. Loss of FMRP is associated with 1) intrinsic hyperexcitability of pyramidal neurons ${ }^{39}$ and 2 ) reduced activity of GABAergic circuits associated with PV cell activity ${ }^{40}$. Therefore, these are promising mechanisms of identified pathologies in FXS. Notably, increased gamma power is associated with the severity of intellectual disability in FXS, demonstrating one of the strongest correlations available of biomarkers with core features of an NDD.

Males with FXS consistently demonstrated greater gamma activity across all cortical regions than females with FXS in both vertex and network level analyses (see Figure 3c), and the association between elevated broadband gamma activity and intellectual disability was primarily driven by male participants. Residual FMRP levels in females may thus have a moderating effect on cortical hyperexcitability as measured by increases in broadband gamma. The distinctive behavioral disturbances in females might be thus more related to their abnormalities in lower frequency long distance modulation in the theta and alpha bands.

\section{Thalamocortical modulation of neocortical hyperexcitability}

Local circuit hyperexcitability is well established in FXS, but our observations of altered lowfrequency modulation extends mechanistic understanding of the illness. Alpha activity, particularly in alpha2, was broadly reduced across node, region, and network comparisons in FXS. Cortical alpha rhythms are primarily generated by thalamocortical signaling with minor contributions from surrounding neocortical regions ${ }^{41}$. Thalamic alterations in FXS have been identified by structural neuroimaging: human infants with FXS display lower fractional anisotropy (FA) between thalamus and neocortex ${ }^{42}$, reduced grey matter density is found in thalamus of FXS adults ${ }^{27}$, and thalamic GABA $_{A}$ receptor density is reduced and correlated with intellectual disability ${ }^{43}$. However, the functional ramifications of these subcortical findings in FXS have remained poorly understood ${ }^{44}$.

Reduction in alpha power and "slowed" alpha frequency has been detected in conditions such as epilepsy, schizophrenia ${ }^{45}$, neuropathic pain, and tinnitus and is referred to as thalamocortical dysrhythmia(TCD) ${ }^{46}$. In tinnitus, an effective deafferentation of central auditory input reduces information flow to the thalamus and a shift of dominant alpha operating frequency $(8-13 \mathrm{~Hz})$ to the theta frequency range $(5-7 \mathrm{~Hz})$ is observed - a shift reminiscent of our data. These cortical regions may demonstrate elevated gamma activity as theta modulation less efficiently drives $\mathrm{GABA}_{\mathrm{A}}$ mediated lateral inhibition than alpha activity. Thus, the canonical role of alpha activity in inhibiting circuits to establish temporal windows for optimal sensory and neurocognitive processing may be diminished. 
medRxiv preprint doi: https://doi.org/10.1101/2021.05.12.21256925; this version posted May 13, 2021. The copyright holder for this preprint (which was not certified by peer review) is the author/funder, who has granted medRxiv a license to display the preprint in perpetuity. It is made available under a CC-BY-NC-ND 4.0 International license .

Presently, all key features of TCD were associated with FXS: 1) a leftward shift or slowing of peak alpha frequency to theta frequency, 2) an anterior redistribution of slowed alpha activity, 3) elevation of broadband gamma activity, and 4) inversion of theta and alpha power coupling with gamma activity ${ }^{21}$. Thus, in addition to well-described cell-intrinsic and local circuit hyperexcitability within the FMRP-deficient cortex, changes in thalamocortical modulation are an important additional feature contributing to increased broad band cortical excitability and intellectual disability. Fmr1 ${ }^{-1-} \mathrm{KO}$ display thalamocortical mediated alterations in experience dependent plasticity of somatosensory cortex ${ }^{44}$. Importantly, the present evidence of cortical hyperexcitability at rest and prior observations of reduced gamma phase locking to auditory stimuli in FXS are conserved in the $\mathrm{Fmr1}^{-1-} \mathrm{KO}$ model ${ }^{11}$. A hypothetical model of TCD in FXS is presented in Figure 4.

The interest in reducing neuronal hyperexcitability in translational models as a therapeutic strategy in FXS requires not only validated translational biomarkers but back-translational approaches to better understand mechanisms and identify novel drug targets. Importantly, these mechanisms may vary based on brain region, developmental period, circuit function, and neuronal type. In some $F m r 1^{-1-} \mathrm{KO}$ circuitry, compensatory mechanisms may partially restore global homeostasis ${ }^{9}$. It is important to consider epilepsy in FXS, as despite heightened excitability, epilepsy is rare (compared to other NDDs), tends to be partial, and often resolves by adulthood or with first-line medications. Thus, while local circuit changes may disrupt specialized circuits for higher-order cognition and sensory processing ${ }^{47}$ but not to the level of representing a common cause of epilepsy. FXS subpopulations with residual FMRP activity (mosaics and female patients) may retain capacity to mount interneuron responses to "sharpen" gamma activity ${ }^{48}$ and, thus, partially spare neural functions as seen in preclinical studies ${ }^{49}$. The roles of FMRP levels in premutation cases remains to be examined.

\section{Limitations}

Although the effect of non-epileptic medications on the results cannot be ruled out, a medication naïve sample would preclude inclusion of more severely affected individuals given the high rate of medication use in FXS. Previous EEG studies of medication effects in psychiatric populations ${ }^{50}$, including our own observations in $\mathrm{FXS}^{14}$, do not suggest effects as we have observed.

\section{Conclusion}

This study of neural oscillatory activity in a relatively large sample of a monogenetic neurodevelopmental disorder provides novel evidence of hyperexcitability in functional brain networks and evidence for reduction in its thalamocortical modulation in FXS. These alterations parallel findings in preclinical models, and have clinical relevance given their association with the severity of intellectual disability. Our data from females with FXS is highly novel and provides evidence for reduced broadband gamma alterations but similar alterations in thalamocortical circuitry as in males. The alterations we observed may contribute to and maintain abnormal cortical states that reduce functional brain connectivity and regional function necessary for higher brain functions. The findings are important in establishing a robust translational strategy for developing and testing new treatments with electrophysiological biomarkers that can transfer directly from mouse model to patient studies. 
medRxiv preprint doi: https://doi.org/10.1101/2021.05.12.21256925; this version posted May 13, 2021. The copyright holder for this preprint (which was not certified by peer review) is the author/funder, who has granted medRxiv a license to display the preprint in perpetuity.

It is made available under a CC-BY-NC-ND 4.0 International license. 
medRxiv preprint doi: https://doi.org/10.1101/2021.05.12.21256925; this version posted May 13, 2021. The copyright holder for this preprint (which was not certified by peer review) is the author/funder, who has granted medRxiv a license to display the preprint in perpetuity. It is made available under a CC-BY-NC-ND 4.0 International license .

\section{Methods}

\section{Participants}

The dataset included a total of 145 participants drawn from a large federally funded human neurophysiology study in FXS (National Institutes of Mental Health U54 HD082008). Exclusion criteria for FXS participants (confirmed by Southern Blot and polymerase chain reaction) included present history of unstable seizures (any treated seizure within one year) and scheduled use of benzodiazepines. Controls did not have treatment for neuropsychiatric illness as reported via clinical interview. All participants provided written informed consent (or assent as appropriate) prior to participation as approved by the institutional review board of Cincinnati Children's Hospital Medical Center. Following blinded preprocessing, three recordings were discarded from further analysis due to excessive line-noise artifact (1 FXS, 2 controls) and one due to insufficient data due to intolerance of the EEG procedure (1 FXS). The final dataset consisted of 70 participants with a genetic diagnosis of full mutation FXS (Mean age $=20.5$, $S D=10$; age range: 5.9-45.7; 32 females) and 71 controls (Mean age $=22.2, S D=10.7$; age range: 5.9-48.2; 30 females). Females with full mutation FXS were included in the primary analyses and effects were confirmed in supplemental analyses of male participants. Age effects were examined in each model for significant fixed effects. Thirty-five FXS patients were on antidepressants and 18 were receiving atypical antipsychotics. These and other concurrent medications were only permitted if participant was on stable dosing for at least 6 weeks.

\section{Data Acquisition and Preprocessing}

Participants were seated comfortably while watching a silent video (standardized across participants) to facilitate cooperation as in previous studies ${ }^{24}$. Dense array raw EEG data is available to the public as federally mandated at the National Database for Autism Research (NDAR). Five minutes of continuous EEG data was collected. Recordings were collected at $1000 \mathrm{~Hz}$ sampling rate with an EGI NetAmp 400 with a 128-channel HydroCel electrode net (Magstim/EGI, Eugene, OR). Preprocessing: All data was blinded and coded in regard to group, participant, or collection date. Data was exported in EGI raw format and imported into EEGLAB SET format in MATLAB (version 2018b, The MathWorks Inc., Natick, MA, USA). To ensure detection of neurogenic activity from the gamma band we followed best-practices to address myogenic contamination ${ }^{51}$. Raw EEG data was filtered using EEGLAB $14.1 .2^{52}$ with a $2 \mathrm{~Hz}$ high pass digital zero-phase filter and a 55 to $65-\mathrm{Hz}$ notch filter (with harmonics removed up to Nyquist frequency of the original sampling rate) to remove line noise. Raw data was visually inspected by an assistant who excluded segments of data with large amount of movement artifact and interpolated bad channels (no more than $5 \%$ per subject) using spherical spline interpolation implemented in EEGLAB 14. Average number of interpolated channels was 6.2 out of 128 (SD=3.5). Data was average referenced. An artifact subspace reconstruction (ASR) approach was carried out with the "clean_rawdata" function (with default parameters) to repair data segments of artifact by applying a reconstruction mixing matrix from non-interpolated neighboring channels. The mixing matrix is computed from clean segments from within the EEG data ${ }^{53}$. Blind source separation was performed with temporal Independent Component Analysis (ICA) on each preprocessed dataset using the extended INFOMAX algorithm ${ }^{54,55}$ with PCA rank reduction (further reduced for interpolated channels). This approach was recently validated to effectively reduce myogenic contamination from approximately $25-98 \mathrm{~Hz}^{18}$. 
medRxiv preprint doi: https://doi.org/10.1101/2021.05.12.21256925; this version posted May 13, 2021. The copyright holder for this preprint (which was not certified by peer review) is the author/funder, who has granted medRxiv a license to display the preprint in perpetuity. It is made available under a CC-BY-NC-ND 4.0 International license .

Resulting components were manually reviewed and categorized for eye movement/blinks, muscle movement, channel noise, or cardiac artifact based on temporospatial and spectral features and back projected to remove artifact. The average number of artifactual components removed $(M=11.3 ; S D=1.5)$ was less than $10 \%$ of resultant components. Resulting nonartifactual independent components are near-independent in time course activity and resemble dipolar scalp projections and have been proposed to represent spatially coherent local field activity within a single cortical area ${ }^{56}$. Data was divided into 2-second epochs and manually reviewed for noise artifacts. Following preprocessing, an average of approximately $256(S D=41)$ seconds or $128(S D=20)$ epochs of artifact-free data remained for each subject.

\section{Source Estimation and Functional Network Definition:}

Minimum norm estimation (MNE) is a widely adopted solution to the inverse problem in which current estimates are calculated at every spatial location in source space to minimize the total power across the cortex ${ }^{57}$. Thus, MNE models, in contrast to dipole fitting, produce uniform maps across subjects which is well-suited for group comparisons and can provide resolution comparable to magnetoencephalography $(M E G)^{58}$. For each subject, the first $80-$ s of artifactfree time series from each of the EGI 128-channel electrodes were co-registered with an Montreal Neurological Institute (MNI) averaged ICBM152 common brain template ${ }^{59}$. The degree of accuracy and precision of EEG source localization is debated, but intracortical recordings during epileptic surgery ${ }^{60}$, surface and deep brain stimulation ${ }^{61}$, and comparisons with functional magnetic resonance imaging $(\mathrm{fMRI})^{62}$ estimate focal localization at $1.5 \mathrm{~cm}$ for superficial neocortex. Thus, even with standard head models and spatial smoothing EEG is suitable for studying high-frequency brain activity in vivo clinical studies ${ }^{63}$. An open M/EEG ${ }^{64}$ was used to compute a 15,000 vertices lead-field mesh incorporating electrode distances. Noise covariance was set as an identity matrix as recommended for scalp resting EEG recordings ${ }^{19}$. Construction of L2-normed, depth-weighted MNE source model to generate a current source density (CSD) map (units: picoampere-meter) was performed in Brainstorm ${ }^{19}$ and used to reconstruct time series activations at each vertex. The Desikan-Killiany (DK) atlas was used to group vertices into 68 cortical regions, of which 44 regions were assigned within resting-state networks ${ }^{20}$. DK atlas regions were classified into five functional brain networks: default mode network (DMN), dorsal attention network (DAN), salient affective network (SAN), auditory network (AUD), and visual network (VIS) based. These dense-EEG derived networks were recently validated following examination of their dynamic properties and compared with networks identified with other neuroimaging techniques (diffusion tensor imaging, functional magnetic resonance imaging, and magnetoencephalography) ${ }^{2}$.

\section{Spectral Power}

Electrode: Estimation of power spectrum density (PSD) was computed from 108 EEG channels which contacted the scalp as a comparison for source analysis. Segmented data (2s) from each channel was detrended, tapered with a Hanning window, and transformed into Fourier coefficients representing $0.5 \mathrm{~Hz}$ frequency steps. To be comparable with our previous study ${ }^{24}$, Fourier coefficients were squared to compute absolute power and divided into 7 bands of interest: delta $(2-3.5 \mathrm{~Hz})$, theta $(4-7.5 \mathrm{~Hz})$, lower alpha (8-10 Hz), upper alpha (10-12.5 Hz), beta (13-30 Hz), and lower gamma (gamma1; 30-55 Hz), and higher gamma (gamma2; 65-90). We opted to split alpha band as functionally as upper alpha bands are associated with more 
medRxiv preprint doi: https://doi.org/10.1101/2021.05.12.21256925; this version posted May 13, 2021. The copyright holder for this preprint (which was not certified by peer review) is the author/funder, who has granted medRxiv a license to display the preprint in perpetuity. It is made available under a CC-BY-NC-ND 4.0 International license .

complex cognitive processing ${ }^{32,65}$, and lower alpha bands have been primarily associated with attentional processes including alertness, expectancy, and vigilance ${ }^{66}$. Relative power was defined as the band-specific cumulative absolute power divided by the total power across all defined bands, and then averaged over available trials. Average dominant frequency (i.e. alpha peak) was determined by the "findpeak" function in MATLAB to identify frequency of the maximum absolute logarithmic power between $6-14 \mathrm{~Hz}$ from each channel's spectrogram ${ }^{67}$.

Source Analysis: Welch's method was used to estimate spectral power from CSD between 2 to $90 \mathrm{~Hz}$ at each vertex with a sliding Hamming window overlapping at $50 \%$. Relative power was calculated by normalizing spectral power per subject and dividing total power from 2-90 $\mathrm{Hz}$ and averaged across identical frequency bands as scalp-EEG analysis. For each subject, PSD results were projected onto the 15,000 vertices cortical source model. To facilitate group comparisons, we used a circularly symmetric Gaussian smoothing kernel with a full width half maximum (FWHM) size of $3 \mathrm{~mm}^{68}$ across all vertices.

\section{Clinical Measures}

Stanford-Binet Intelligence Scale 5th Ed. (SBS) ${ }^{69}$ was conducted by trained clinicians in both FXS and control participants. Due to floor effects, deviation IQ scores ${ }^{70}$ were computed to capture variability in cognitive functioning. Assessments were completed by the primary caregivers for FXS patients including the Social Communication Questionnaire (SCQ $)^{71}$, Anxiety, Depression, and Mood Scale (ADAMS) ${ }^{72}$, Woodcock-Johnson III Tests of Cognitive Abilities, Auditory Attention subscale (WJ3) ${ }^{73}$.

Statistics:

Software: Statistical analysis was performed with MATLAB 2018b (MathWorks, Natick, MA, USA), SAS 9.4 (SAS Institute Inc., Cary, NC, USA), and R (4.0, Vienna, Austria). Power and Sample Size: Differences in gamma1 power in FXS compared to controls in previous studies have effect sizes from .63 to 1.75, similar to effect sizes in prior studies of N1 amplitudes in $\mathrm{FXS}^{6,14,24,74}$. Based on these effect sizes, comparing $70 \mathrm{FXS}$ patients ( $50 \%$ males) and $70 \mathrm{TD}$ controls provides power to detect the primary EEG outcome with approximately power $>.90$ (using an omnibus F-test with an alpha of .05). In line with reproducible research guidelines, scripts for generation of figures and tables are available upon request.

\section{Group comparisons:}

Electrode-based spectral power comparison: Cluster-based permutation analysis ${ }^{75}$ was used to identify significant differences between FXS and controls in relative power electrode by electrode between frequency bands. Overall alpha was set at .05 / 7 (adj. p.<.007) to account for multiple band comparisons (effective alpha for each tail .025). Source-localized spectral power comparison: Group-level statistical (t-statistic) maps were assessed by Monte-Carlo permutation (2000) independent two-tailed t-tests (alpha set at .025 per tail) using the 'ft_sourcestatistics' function in FieldTrip ${ }^{76}$ and threshold at $\mathrm{P}<.05$. The resulting $\mathrm{p}$ values were globally corrected by a false discovery rate (FDR) of $5 \%$ applied over the signals and frequency band dimensions ${ }^{77}$.

Node and Network Comparisons: 
medRxiv preprint doi: https://doi.org/10.1101/2021.05.12.21256925; this version posted May 13, 2021. The copyright holder for this preprint (which was not certified by peer review) is the author/funder, who has granted medRxiv a license to display the preprint in perpetuity. It is made available under a CC-BY-NC-ND 4.0 International license .

Log-transformed relative power differences were evaluated with generalized linear mixed models via the GLIMMIX procedure ${ }^{78}$ in SAS 9.4 (SAS Institute Inc., Cary, NC, USA) in which random effect was subject and independent variable varied based on model. Vertex-by-vertex model: LME included fixed effects of group (FXS vs. control), node (68 atlas nodes), and seven frequency bands on log-transformed relative power. RSNs: Group: Model included fixed effects of Group (FXS vs. control), RSN (DMN, VIS, DAN, SAN, vs AUD), seven Frequency bands, and DK atlas nodes. Sex Differences: The final fitted model included subject as the random effect and fixed effects of Group (FXS vs. control), Sex (M vs. F), RSN (DMN, VIS, DAN, SAN, vs AUD), and seven Frequency bands. In this model atlas nodes within each RSN were treated as replicates. Different link functions and intra-subject covariance structures were examined. Plots based on the studentized residuals were examined in each case.

\section{Alpha-shift Distribution:}

An LME was conducted to assess CFC differences in which the random effect was subject and with fixed effects of group (FXS vs. control), sex (male vs. female), and lower CFC band (theta vs. alpha) on gamma1 amplitude-amplitude coupling (AAC). We examined within group alphashift changes along the occipital-frontal axis using an LME to model log-transformed $\alpha_{\text {shift }}$ with fixed effects of group (FXS, Control), sex (M vs. F), and occipital-frontal axis region (occipital, parietal, central, and frontal; composed of atlas nodes) with the final fitted model including subject as the random effect and controlling for age.

\section{Cross frequency amplitude coupling:}

To examine potential dependence between low-frequency activity and high-frequency activity, we evaluated cross-frequency amplitude-amplitude coupling (AAC) consistent with previous reporting ${ }^{24}$ with low-frequency band candidates, theta and alpha band $(8-12.5 \mathrm{~Hz})$, with gamma1 or gamma2. CSD time series from each DMN node were segmented into 2-s epochs. Relative powers per epoch from the selected band candidates contributed to the Spearman Correlation for all DMN nodes. Normalization via Fisher's Z-transform was applied for groupwise comparisons.

\section{Correlation analysis}

As a successive step, frequency bands of significance were linearly correlated with clinical and behavioral measures. Primary Analysis: Shapiro-Wilk's normality test was performed on variables to assess suitability for either Spearman's rank-order or Pearson's correlation test. A priori hypotheses for high-frequency bands (beta, gamma1, and gamma2) and low-frequency bands (theta, alpha1, and alpha2) with clinical variables were assessed with correlation tests with $p$ values adjusted by FDR for multiple test iterations and partial correlations were used to adjust all correlations for age. 
medRxiv preprint doi: https://doi.org/10.1101/2021.05.12.21256925; this version posted May 13, 2021. The copyright holder for this preprint (which was not certified by peer review) is the author/funder, who has granted medRxiv a license to display the preprint in perpetuity. It is made available under a CC-BY-NC-ND 4.0 International license .

\section{References and Notes:}

1. Damoiseaux, J.S., et al. Consistent resting-state networks across healthy subjects. Proceedings of the National Academy of Sciences of the United States of America 103, 1384813853 (2006).

2. Kabbara, A., El Falou, W., Khalil, M., Wendling, F. \& Hassan, M. The dynamic functional core network of the human brain at rest. Sci Rep 7, 2936 (2017).

3. Thapar, A., Cooper, M. \& Rutter, M. Neurodevelopmental disorders. Lancet Psychiatry 4, 339-346 (2017).

4. $\quad$ Ewen, J.B., Sweeney, J.A. \& Potter, W.Z. Conceptual, Regulatory and Strategic Imperatives in the Early Days of EEG-Based Biomarker Validation for Neurodevelopmental Disabilities. Front Integr Neurosci 13, 45 (2019).

5. Morin-Parent, F., Champigny, C., Lacroix, A., Corbin, F. \& Lepage, J.F. Hyperexcitability and impaired intracortical inhibition in patients with fragile-X syndrome. Trans/ Psychiatry 9, 312 (2019).

6. Ethridge, L.E., et al. Neural synchronization deficits linked to cortical hyper-excitability and auditory hypersensitivity in fragile X syndrome. Mol Autism 8, 22 (2017).

7. Santoro, M.R., Bray, S.M. \& Warren, S.T. Molecular mechanisms of fragile X syndrome: a twenty-year perspective. Annual review of pathology 7, 219-245 (2012).

8. Goswami, S., Cavalier, S., Sridhar, V., Huber, K.M. \& Gibson, J.R. Local cortical circuit correlates of altered EEG in the mouse model of Fragile X syndrome. Neurobiol Dis 124, 563572 (2019).

9. $\quad$ Antoine, M.W., Langberg, T., Schnepel, P. \& Feldman, D.E. Increased ExcitationInhibition Ratio Stabilizes Synapse and Circuit Excitability in Four Autism Mouse Models. Neuron 101, 648-661 e644 (2019).

10. Lovelace, J.W., et al. Deletion of Fmr1 from Forebrain Excitatory Neurons Triggers Abnormal Cellular, EEG, and Behavioral Phenotypes in the Auditory Cortex of a Mouse Model of Fragile X Syndrome. Cereb Cortex 30, 969-988 (2020).

11. Lovelace, J.W., Ethell, I.M., Binder, D.K. \& Razak, K.A. Translation-relevant EEG phenotypes in a mouse model of Fragile X Syndrome. Neurobiol Dis 115, 39-48 (2018).

12. Jonak, C.R., Lovelace, J.W., Ethell, I.M., Razak, K.A. \& Binder, D.K. Multielectrode array analysis of EEG biomarkers in a mouse model of Fragile X Syndrome. Neurobiol Dis 138, 104794 (2020).

13. Gibson, J.R., Bartley, A.F., Hays, S.A. \& Huber, K.M. Imbalance of neocortical excitation and inhibition and altered UP states reflect network hyperexcitability in the mouse model of fragile X syndrome. J Neurophysiol 100, 2615-2626 (2008).

14. Ethridge, L.E., et al. Auditory EEG Biomarkers in Fragile X Syndrome: Clinical Relevance. Front Integr Neurosci 13, 60 (2019).

15. Schmitt, L.M., et al. A neurophysiological model of speech production deficits in fragile $X$ syndrome. Brain Commun 2, fcz042 (2020).

16. van der Molen, M.J., Stam, C.J. \& van der Molen, M.W. Resting-state EEG oscillatory dynamics in fragile $X$ syndrome: abnormal functional connectivity and brain network organization. PLoS One 9, e88451 (2014). 
medRxiv preprint doi: https://doi.org/10.1101/2021.05.12.21256925; this version posted May 13, 2021. The copyright holder for this preprint (which was not certified by peer review) is the author/funder, who has granted medRxiv a license to display the preprint in perpetuity. It is made available under a CC-BY-NC-ND 4.0 International license .

17. Mably, A.J. \& Colgin, L.L. Gamma oscillations in cognitive disorders. Curr Opin Neurobiol 52, 182-187 (2018).

18. Fitzgibbon, S.P., et al. Automatic determination of EMG-contaminated components and validation of independent component analysis using EEG during pharmacologic paralysis. Clin Neurophysiol 127, 1781-1793 (2016).

19. Tadel, F., Baillet, S., Mosher, J.C., Pantazis, D. \& Leahy, R.M. Brainstorm: a userfriendly application for MEG/EEG analysis. Comput Intell Neurosci 2011, 879716 (2011).

20. Desikan, R.S., et al. An automated labeling system for subdividing the human cerebral cortex on MRI scans into gyral based regions of interest. Neuroimage 31, 968-980 (2006).

21. Vanneste, S., Song, J.J. \& De Ridder, D. Thalamocortical dysrhythmia detected by machine learning. Nat Commun 9, 1103 (2018).

22. Llinas, R.R., Ribary, U., Jeanmonod, D., Kronberg, E. \& Mitra, P.P. Thalamocortical dysrhythmia: A neurological and neuropsychiatric syndrome characterized by magnetoencephalography. Proceedings of the National Academy of Sciences of the United States of America 96, 15222-15227 (1999).

23. Jensen, O. \& Colgin, L.L. Cross-frequency coupling between neuronal oscillations. Trends in Cognitive Sciences 11, 267-269 (2007).

24. Wang, J., et al. A resting EEG study of neocortical hyperexcitability and altered functional connectivity in fragile $X$ syndrome. Journal of neurodevelopmental disorders $\mathbf{9}, 11$ (2017).

25. Ribary, U., Doesburg, S.M. \& Ward, L.M. Unified Principles of Thalamocortical Network Dynamics: A Framework for Typical/Atypical Functional Connectivity.

Magnetoencephalography: From Signals to Dynamic Cortical Networks, 543-570 (2019).

26. Abela, E., et al. Slower alpha rhythm associates with poorer seizure control in epilepsy. Ann Clin Transl Neurol 6, 333-343 (2019).

27. Hall, S.S., Jiang, H., Reiss, A.L. \& Greicius, M.D. Identifying large-scale brain networks in fragile X syndrome. JAMA Psychiatry 70, 1215-1223 (2013).

28. de Pasquale, F., et al. A cortical core for dynamic integration of functional networks in the resting human brain. Neuron 74, 753-764 (2012).

29. Scerif, G., Longhi, E., Cole, V., Karmiloff-Smith, A. \& Cornish, K. Attention across modalities as a longitudinal predictor of early outcomes: the case of fragile $X$ syndrome. $J$ Child Psychol Psychiatry 53, 641-650 (2012).

30. Seeley, W.W., et al. Dissociable intrinsic connectivity networks for salience processing and executive control. J Neurosci 27, 2349-2356 (2007).

31. Rais, M., Binder, D.K., Razak, K.A. \& Ethell, I.M. Sensory Processing Phenotypes in Fragile X Syndrome. ASN Neuro 10, 1759091418801092 (2018).

32. Klimesch, W., Sauseng, P. \& Hanslmayr, S. EEG alpha oscillations: the inhibition-timing hypothesis. Brain Res Rev 53, 63-88 (2007).

33. Chen, A.C., Feng, W., Zhao, H., Yin, Y. \& Wang, P. EEG default mode network in the human brain: spectral regional field powers. Neuroimage 41, 561-574 (2008).

34. Ward, A.M., et al. The parahippocampal gyrus links the default-mode cortical network with the medial temporal lobe memory system. Hum Brain Mapp 35, 1061-1073 (2014).

35. Bartoli, E., et al. Functionally Distinct Gamma Range Activity Revealed by Stimulus Tuning in Human Visual Cortex. Curr Biol 29, 3345-3358 e3347 (2019). 
medRxiv preprint doi: https://doi.org/10.1101/2021.05.12.21256925; this version posted May 13, 2021. The copyright holder for this preprint (which was not certified by peer review) is the author/funder, who has granted medRxiv a license to display the preprint in perpetuity. It is made available under a CC-BY-NC-ND 4.0 International license .

36. Kogan, C.S., et al. Differential impact of the FMR1 gene on visual processing in fragile $X$ syndrome. Brain 127, 591-601 (2004).

37. Scheeringa, R., et al. Neuronal dynamics underlying high- and low-frequency EEG oscillations contribute independently to the human BOLD signal. Neuron 69, 572-583 (2011). 38. Cho, K.K., et al. Gamma rhythms link prefrontal interneuron dysfunction with cognitive inflexibility in DIx5/6(+/-) mice. Neuron 85, 1332-1343 (2015).

39. Contractor, A., Klyachko, V.A. \& Portera-Cailliau, C. Altered Neuronal and Circuit Excitability in Fragile X Syndrome. Neuron 87, 699-715 (2015).

40. Franco, L.M., Okray, Z., Linneweber, G.A., Hassan, B.A. \& Yaksi, E. Reduced Lateral Inhibition Impairs Olfactory Computations and Behaviors in a Drosophila Model of Fragile $X$ Syndrome. Curr Biol 27, 1111-1123 (2017).

41. Crunelli, V., et al. Dual function of thalamic low-vigilance state oscillations: rhythmregulation and plasticity. Nature reviews. Neuroscience 19, 107-118 (2018).

42. Swanson, M.R., et al. Development of White Matter Circuitry in Infants With Fragile X Syndrome. JAMA Psychiatry 75, 505-513 (2018).

43. D'Hulst, C., et al. Positron Emission Tomography (PET) Quantification of GABAA Receptors in the Brain of Fragile X Patients. PLoS One 10, e0131486 (2015).

44. Domanski, A.P.F., Booker, S.A., Wyllie, D.J.A., Isaac, J.T.R. \& Kind, P.C. Cellular and synaptic phenotypes lead to disrupted information processing in Fmr1-KO mouse layer 4 barrel cortex. Nat Commun 10, 4814 (2019).

45. Lakatos, P., et al. The Thalamocortical Circuit of Auditory Mismatch Negativity. Biol Psychiatry 87, 770-780 (2020).

46. Llinas, R., Urbano, F.J., Leznik, E., Ramirez, R.R. \& van Marle, H.J. Rhythmic and dysrhythmic thalamocortical dynamics: GABA systems and the edge effect. Trends Neurosci 28, 325-333 (2005).

47. Yizhar, O., et al. Neocortical excitation/inhibition balance in information processing and social dysfunction. Nature 477, 171-178 (2011).

48. Cardin, J.A., et al. Driving fast-spiking cells induces gamma rhythm and controls sensory responses. Nature 459, 663-667 (2009).

49. Graef, J.D., et al. Partial FMRP expression is sufficient to normalize neuronal hyperactivity in Fragile X neurons. Eur J Neurosci 51, 2143-2157 (2020).

50. Clementz, B.A., et al. Identification of Distinct Psychosis Biotypes Using Brain-Based Biomarkers. Am J Psychiatry 173, 373-384 (2016).

51. Hipp, J.F. \& Siegel, M. Dissociating neuronal gamma-band activity from cranial and ocular muscle activity in EEG. Front Hum Neurosci 7, 338 (2013).

52. Delorme, A. \& Makeig, S. EEGLAB: an open source toolbox for analysis of single-trial EEG dynamics including independent component analysis. J Neurosci Methods 134, 9-21 (2004).

53. Chang, C.Y., Hsu, S.H., Pion-Tonachini, L. \& Jung, T.P. Evaluation of Artifact Subspace Reconstruction for Automatic Artifact Components Removal in Multi-Channel EEG Recordings. IEEE Trans Biomed Eng 67, 1114-1121 (2020).

54. Lee, T.W., Girolami, M. \& Sejnowski, T.J. Independent component analysis using an extended infomax algorithm for mixed subgaussian and supergaussian sources. Neural Comput 11, 417-441 (1999). 
medRxiv preprint doi: https://doi.org/10.1101/2021.05.12.21256925; this version posted May 13, 2021. The copyright holder for this preprint (which was not certified by peer review) is the author/funder, who has granted medRxiv a license to display the preprint in perpetuity. It is made available under a CC-BY-NC-ND 4.0 International license .

55. Mullen, T.R., et al. Real-Time Neuroimaging and Cognitive Monitoring Using Wearable Dry EEG. IEEE Trans Biomed Eng 62, 2553-2567 (2015).

56. Delorme, A., Palmer, J., Onton, J., Oostenveld, R. \& Makeig, S. Independent EEG sources are dipolar. PLoS One 7, e30135 (2012).

57. Hamalainen, M.S. \& IImoniemi, R.J. Interpreting magnetic fields of the brain: minimum norm estimates. Med Biol Eng Comput 32, 35-42 (1994).

58. Komssi, S., Huttunen, J., Aronen, H.J. \& IImoniemi, R.J. EEG minimum-norm estimation compared with MEG dipole fitting in the localization of somatosensory sources at S1. Clin Neurophysiol 115, 534-542 (2004).

59. Fonov, V., et al. Unbiased average age-appropriate atlases for pediatric studies. Neuroimage 54, 313-327 (2011).

60. Brodbeck, V., et al. Electroencephalographic source imaging: a prospective study of 152 operated epileptic patients. Brain 134, 2887-2897 (2011).

61. Seeber, M., et al. Subcortical electrophysiological activity is detectable with high-density EEG source imaging. Nat Commun 10, 753 (2019).

62. Lascano, A.M., et al. Surgically relevant localization of the central sulcus with highdensity somatosensory-evoked potentials compared with functional magnetic resonance imaging. Neurosurgery 74, 517-526 (2014).

63. Russell, G., et al. Selection bias on intellectual ability in autism research: a crosssectional review and meta-analysis. Mol Autism 10, 9 (2019).

64. Gramfort, A., Papadopoulo, T., Olivi, E. \& Clerc, M. OpenMEEG: opensource software for quasistatic bioelectromagnetics. Biomed Eng Online 9, 45 (2010).

65. Klimesch, W. EEG alpha and theta oscillations reflect cognitive and memory performance: a review and analysis. Brain Res Brain Res Rev 29, 169-195 (1999).

66. Klimesch, W., Doppelmayr, M., Russegger, H., Pachinger, T. \& Schwaiger, J. Induced alpha band power changes in the human EEG and attention. Neurosci Lett 244, 73-76 (1998). 67. Scally, B., Burke, M.R., Bunce, D. \& Delvenne, J.F. Resting-state EEG power and connectivity are associated with alpha peak frequency slowing in healthy aging. Neurobiol Aging 71, 149-155 (2018).

68. Worsley, K.J., et al. A Matlab toolbox for the statistical analysis of univariate and multivariate surface and volumetric data using linear mixed effects models and random field theory. in Neurolmage Organisation for Human Brain Mapping 2009 Annual Meeting S102 (2009).

69. G, R. Stanford-Binet Intelligence Scales. (Nelson Education., Scarborough, Ontario, 2003).

70. Sansone, S.M., et al. Improving IQ measurement in intellectual disabilities using true deviation from population norms. Journal of neurodevelopmental disorders 6, 16 (2014). 71. Rutter, M., Bailey, A. \& Lord, C. The Social Communication Questionnaire: Manual (Western Psychological Services, Torrence, California, 2003).

72. Esbensen, A.J., Rojahn, J., Aman, M.G. \& Ruedrich, S. Reliability and validity of an assessment instrument for anxiety, depression, and mood among individuals with mental retardation. J Autism Dev Disord 33, 617-629 (2003).

73. McGrew, K.S. \& Woodcock, R.W. Woodcock-Johnson III Technical Manual: WJ III (Riverside Publ., 2006). 
74. Ethridge, L.E., et al. Reduced habituation of auditory evoked potentials indicate cortical hyper-excitability in Fragile X Syndrome. Transl Psychiatry 6, e787 (2016).

75. Maris, E. \& Oostenveld, R. Nonparametric statistical testing of EEG- and MEG-data. J Neurosci Methods 164, 177-190 (2007).

76. Oostenveld, R., Fries, P., Maris, E. \& Schoffelen, J.M. FieldTrip: Open source software for advanced analysis of MEG, EEG, and invasive electrophysiological data. Comput Intell Neurosci 2011, 156869 (2011).

77. Benjamini, Y. \& Hochberg, Y. Controlling the False Discovery Rate - a Practical and Powerful Approach to Multiple Testing. J R Stat Soc B 57, 289-300 (1995).

78. Schabenberger, O. Introducing the GLIMMIX procedure for generalized linear mixed models. 
medRxiv preprint doi: https://doi.org/10.1101/2021.05.12.21256925; this version posted May 13, 2021. The copyright holder for this preprint (which was not certified by peer review) is the author/funder, who has granted medRxiv a license to display the preprint in perpetuity.

It is made available under a CC-BY-NC-ND 4.0 International license .

\section{Figures:}

(A) Overview of methodology

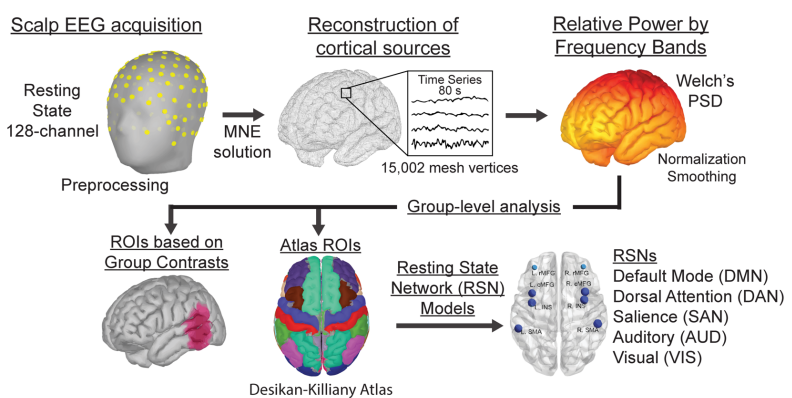

(B) Intellectual disability by group and sex

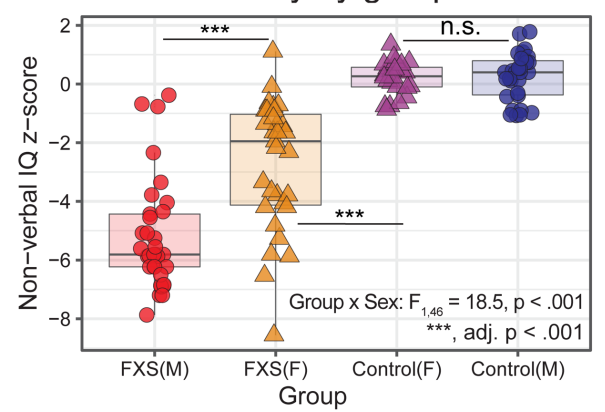

(C) Spectrogram of Scalp EEG Relative Power (D) Cortical source estimates of power contrasts (FXS-Con-

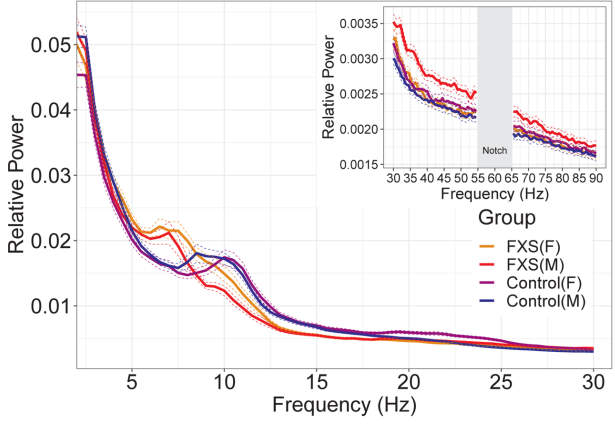

(E) Subject distribution of sig. power differenc-

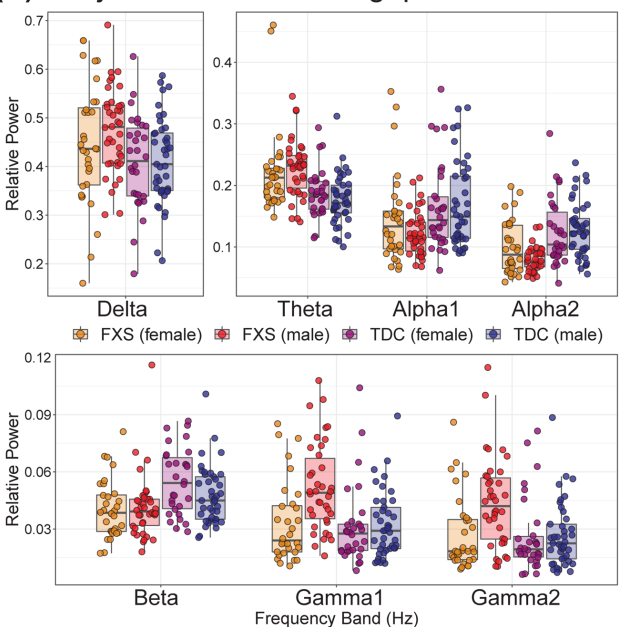

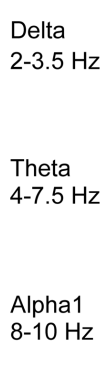

Alpha2 10.5$12.5 \mathrm{~Hz}$ Beta 13-30 Hz Gamma1
30-55 Hz

Gamma2 $65-90 \mathrm{~Hz}$
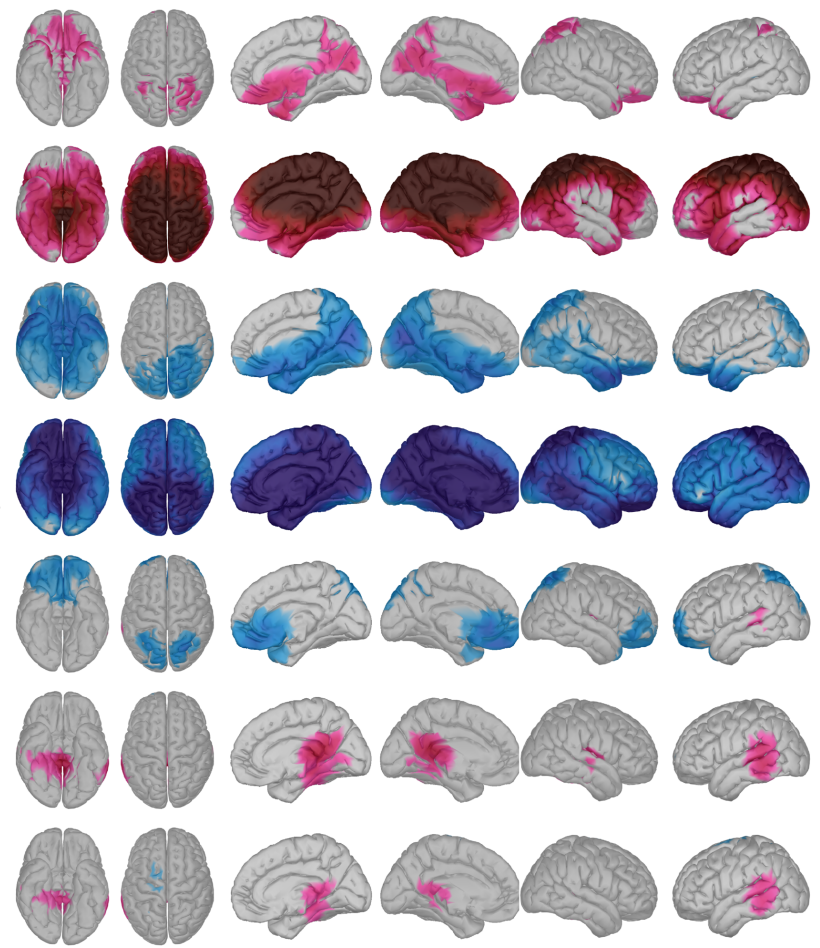

Superior

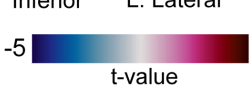

R. Lateral L. Sagittal

R. Sagittal

5 Cooler colors indicated FXS $<$ TDC Warmer colors indicate FXS > TDC

Figure 1. Spectral alterations suggestive of neocortical hyperexcitability in FXS. Scalp and source-localization of dense array electroencephalography (EEG) suggest broadband power disruptions in frequency oscillations in FXS $(n=70)$ compared to age- and sexmatched controls $(n=71)$. (A) Principal steps of the investigative method: Following blinded preprocessing, artifact-free EEG data and a cortical lead field matrix was used to 
construct a weighted minimum norm estimate (MNE) to reconstruct source estimations. Current source density (CSD) by frequency band was used to calculate 1) vertex by vertex differences between groups, 2) generate contrast independent time series for Desikan-Killany atlas nodes based on the atlas, and 3) hierarchical groupings into EEGdefined resting-state networks (RSN). (B) Subject-level scatter plot of intellectual disability as estimated by non-verbal intelligence z-scores (NVIQ) by allele group. (C) Frequency spectrogram of mean scalp EEG relative power (thick lines) with $95 \%$ confidence intervals (dotted tracings) by group and sex. Peak frequency is reduced in FXS males $(M=8.0 \mathrm{~Hz}, S D=1.8)$ and females $(M=8.6 \mathrm{~Hz}, S D=1.7)$ compared to control males $(M=9.3 \mathrm{~Hz}, S D=1.8)$ and females $(M=9.6 \mathrm{~Hz}, S D=1.7)$ with a prominent effect of Group: $F_{1,133}=38.24, p=1.5 \times 10^{-9}$. No interaction effect or effect of age $\left(F_{1,133}=.02\right.$, $\mathrm{p}=.89$ ) on peak alpha frequency was evident. Inset: Isolated depiction of gamma frequencies $(30-90 \mathrm{~Hz})$ illustrating gross elevation of gamma activity in FXS males. (D) Group level t-maps depicting FXS - control, vertex-by-vertex relative power differences by frequency band superimposed on brain surface models. Warmer (FXS > Control) and cooler (FXS < Control) color scale represents significant t-values (non-significant values as gray). (E) Boxplots displaying median and interquartile range of relative power by frequency band (split into subplots by frequency band to optimize scale), averaged for each significant ROI from group level t-maps. Subject level data is superimposed as a scatterplot. 
medRxiv preprint doi: https://doi.org/10.1101/2021.05.12.21256925; this version posted May 13, 2021. The copyright holder for this preprint (which was not certified by peer review) is the author/funder, who has granted medRxiv a license to display the preprint in perpetuity.

It is made available under a CC-BY-NC-ND 4.0 International license .

(A) Lower peak frequency in FXS across default mode network (DMN)

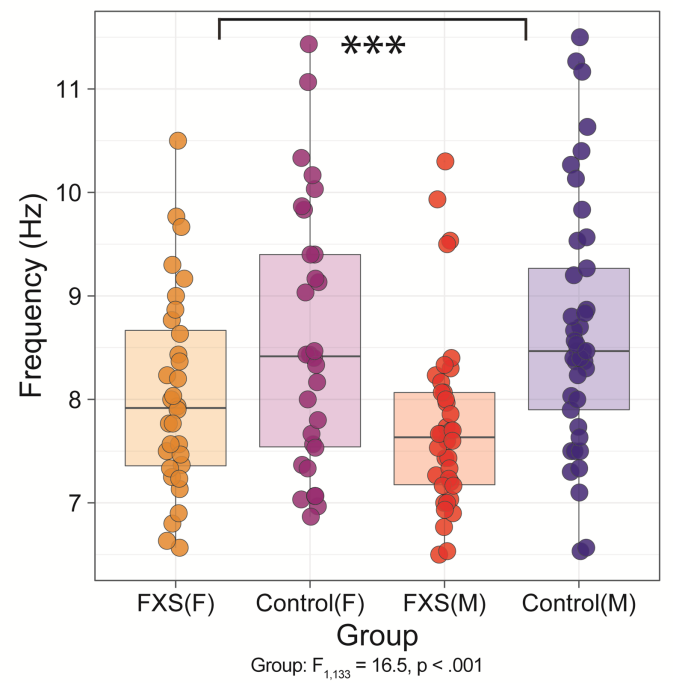

(B) Inverted alpha vs. theta with gamma1 amplitude coupling of DMN in FXS

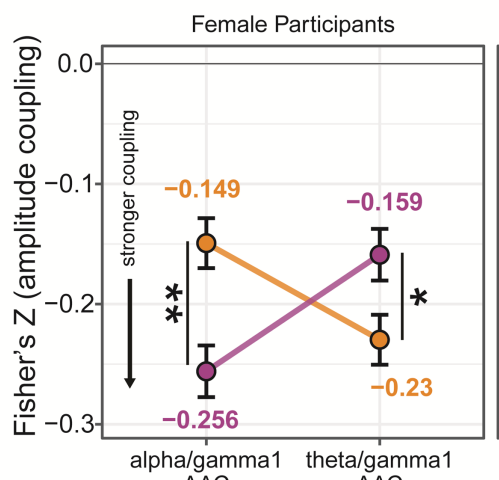

AAC

low-frequency band coupled with gamma1

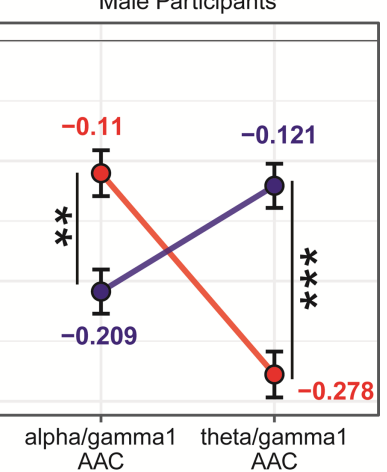

OFXS (F)

OFXS (M)

n.s., non-significant $\quad *$, adj. $p<.05$

OControl (F) OControl (M)

$\stackrel{*}{*}, \operatorname{adj} . p<1 \times 10^{-4}$

(C) Alpha power is slowed and anteriorly distributed in FXS patients (paired subject data)
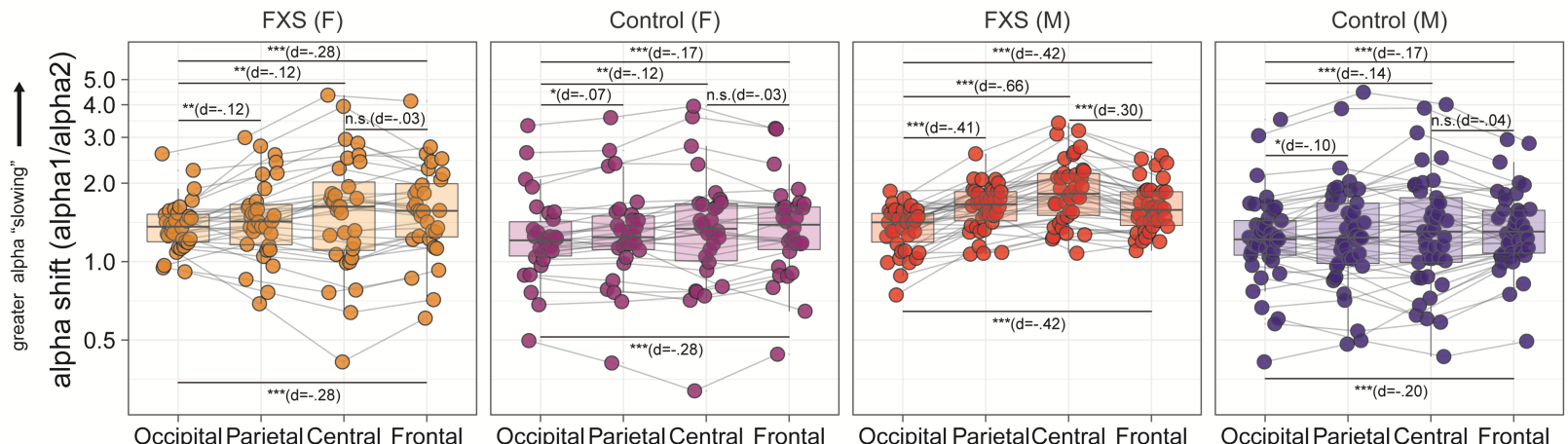

Occipital Parietal Central Frontal Occipital ParietalCent
Cortex Region (Posterior to Anterior)

(D) Signficant alpha-rhythm slowing and anterior spread in male patients with FXS

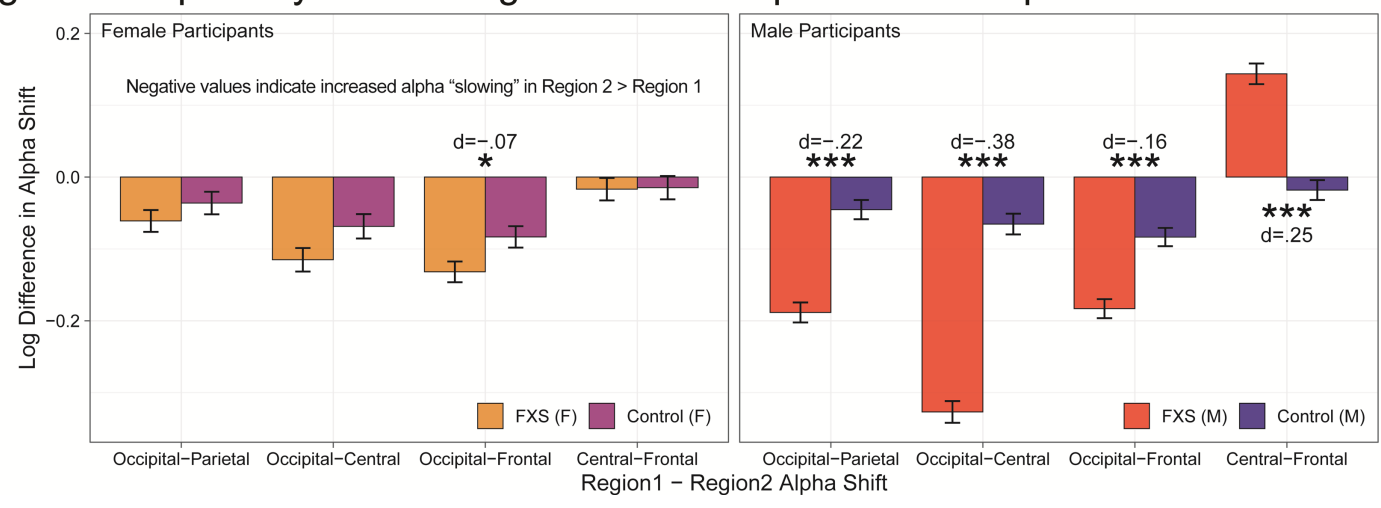


medRxiv preprint doi: https://doi.org/10.1101/2021.05.12.21256925; this version posted May 13, 2021. The copyright holder for this preprint (which was not certified by peer review) is the author/funder, who has granted medRxiv a license to display the preprint in perpetuity. It is made available under a CC-BY-NC-ND 4.0 International license .

Figure 2 Features supporting thalamocortical dysrhythmia (TCD) in FXS patients. In several neuropsychiatric conditions, pathological slowing of alpha oscillations is observed across M/EEG and intraoperative LFP recordings suggesting abnormalities in thalamocortical activity. Fmr1 ${ }^{-/-} \mathrm{KO}$ studies demonstrate dysregulated activity at the thalamic level leading to aberrant entrainment of cortical networks, but thalamocortical signaling is poorly understood in FXS patients. (A) Boxplot (median and interquartile range with superimposed subject-level data) demonstrating leftward shift of mean peak alpha frequency within DMN nodes in FXS patients compared to age- and sex-matched controls. (B) Interaction plot of theta and total alpha (8-13.5 Hz) cross-frequency amplitude/amplitude coupling (AAC) with gamma1 power demonstrating that amplitude/amplitude coupling relationships are inverted in patients versus controls (vertical black bars, significant following FDR-adjusted post-hoc testing). (C) Slowing of alpha power in males with FXS with prominent "anteriorized" distribution. Bar plots (median and interquartile range with superimposed subject-level data) depict group statistical comparisons of alpha1/alpha2 ratio (higher values indicate greater proportion of low-alpha power) by group and sex across midline cortical regions (horizontal black bar, post-hoc testing: *, adj. p <.05; ${ }^{* * *}$, adj. p. $<1 \times 10^{-5}$ ). (D) Bar plots (mean \pm standard error of least-squared mean estimates) depicting between group contrasts demonstrate males with FXS have greater proportion of "slow" alpha activity in central and frontal cortices than age-matched controls (horizontal black bars, FDR-adjusted, post-hoc testing between FXS versus matched control groups). FDR-adjusted $p$ values, ${ }^{*}$, adj. $p<$ $.05 ;{ }^{* *}$, adj. p. $<1 \times 10^{-5}$. 
medRxiv preprint doi: https://doi.org/10.1101/2021.05.12.21256925; this version posted May 13, 2021. The copyright holder for this preprint (which was not certified by peer review) is the author/funder, who has granted medRxiv a license to display the preprint in perpetuity.

It is made available under a CC-BY-NC-ND 4.0 International license .

(A) Relative power differences (FXS - Control) within default mode network (DMN)
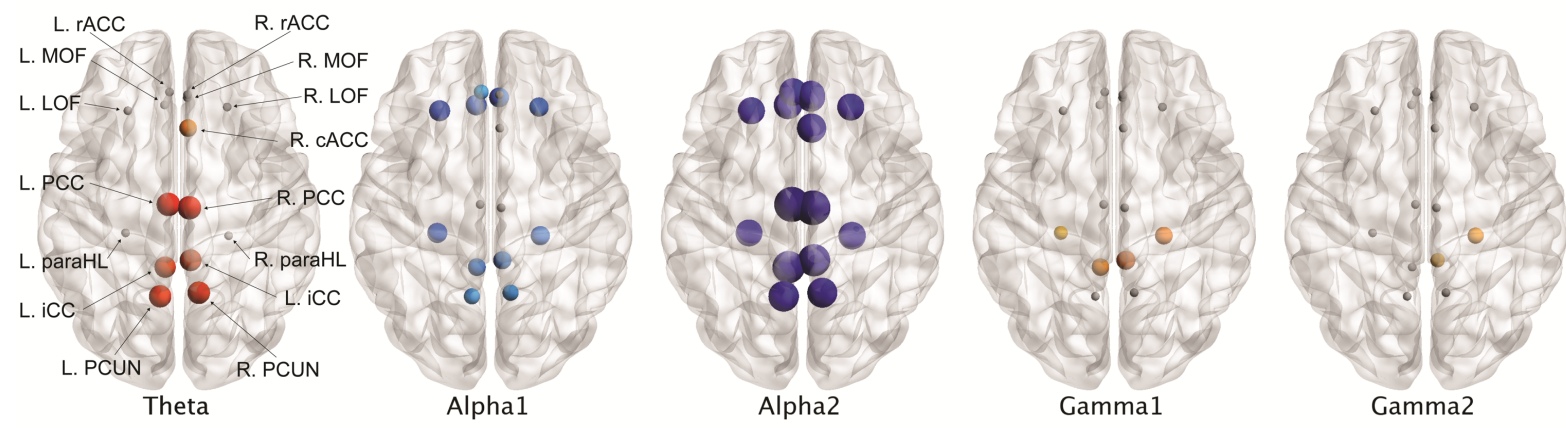

FDR corrected $-6{ }^{\text {t-value }} 6$ Cooler colors: FXS < Control Warmer colors: FXS > Control

(B) Resting state networks (RSN) in relative power differences (FXS - TDC) by sex FXS Male - Control Male
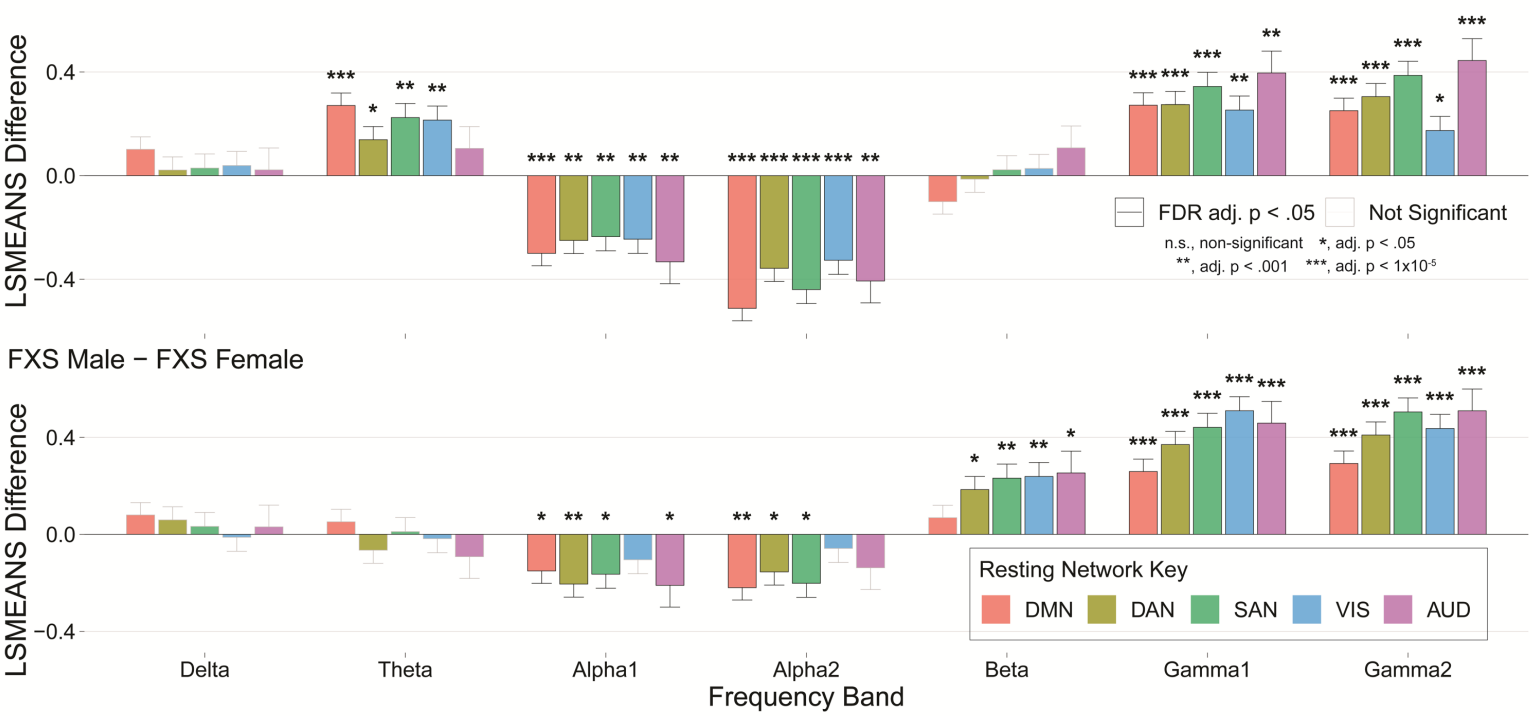

(C) Correlation of intellectual disability in FXS with mean DMN Gamma Power

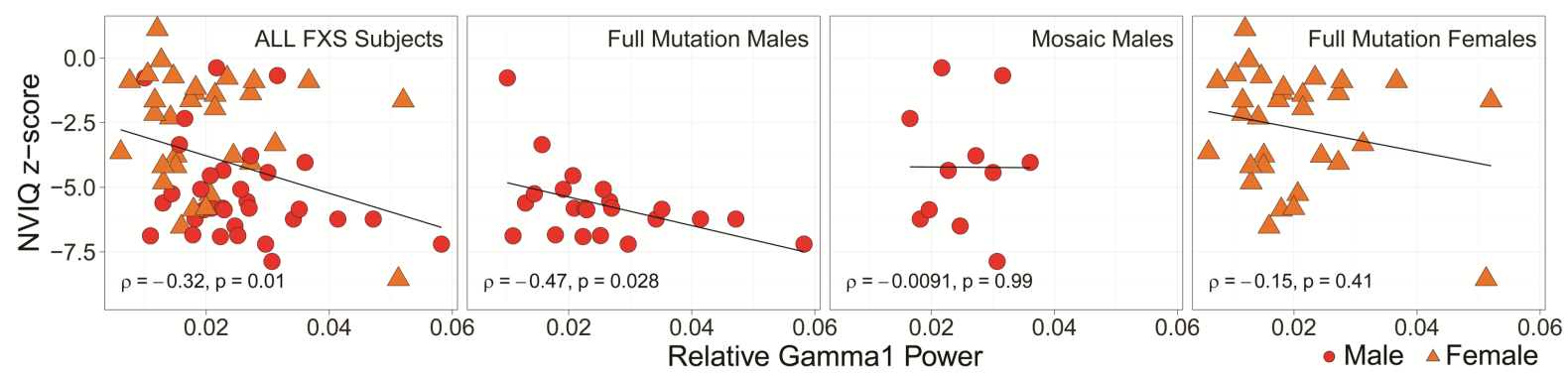

(D) Correlation of Anxiety in FXS with mean VIS Alpha2 Power

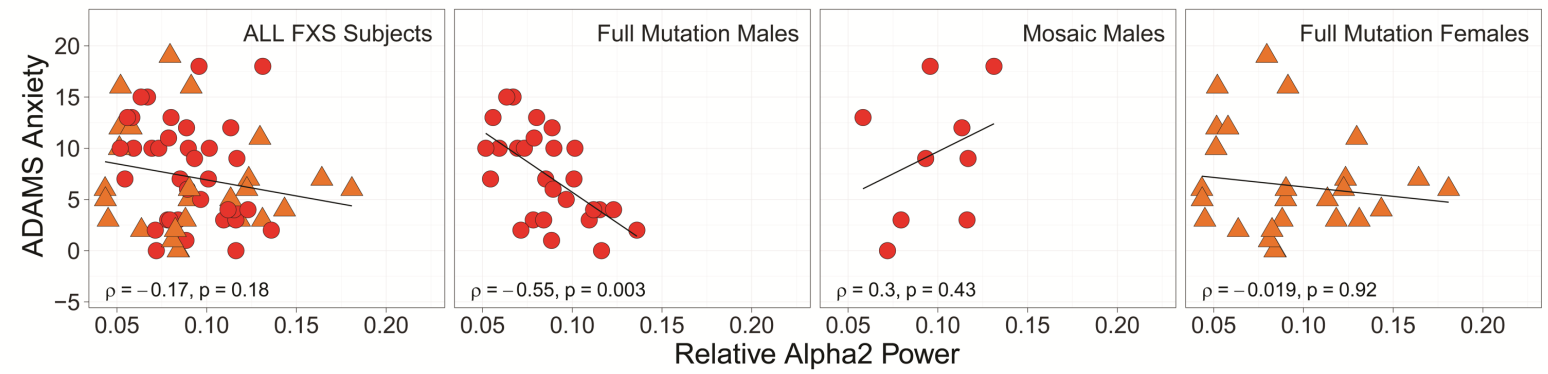


Figure 3. Hyperexcitability (reduced alpha and increased gamma power) in default mode network (DMN) and relationship to intellectual disability in FXS. (A) FDR-corrected group-level t-maps depicting significant differences in node-by-node relative power across DMN. Size of node is scaled by absolute t-value to enhance visualization of contrasts. Gray nodes indicate non-significant contrasts. (B) Profile of resting state network (RSNs) differences of males with FXS compared to control males and females with FXS. Obligate mosaicism present Fmr1 in females with full mutation FXS may attenuate elevated gamma power. Group-level contrasts in log-normalized relative power by frequency band of functional resting-state networks (RSNs) depicted in bar plots of least-squared mean estimates (mean \pm standard error). Black outlined bars indicate frequency band and network pair is statistically significant $(p<.05$, FDR corrected). Gray outlined bars did not reach statistical significance. (C) Non-verbal intelligence quotient (NVIQ) is a general measure of intelligence which is not dependent on verbal abilities. NVIQ is inversely related to mean gamma1 power of DMN nodes across all FXS subjects, with the association primarily driven by full mutation males with FXS. (D) Severity of anxiety is inversely associated with alpha2 power derived from the visual network. Resting state network abbreviations: DMN, default mode network; DAN, dorsal attention network; SAN, salient affective network; VIS, visual attention network; AUD, auditory network. 


\section{Proposed Model of Thalamocortical Dysrhythmia in FXS}

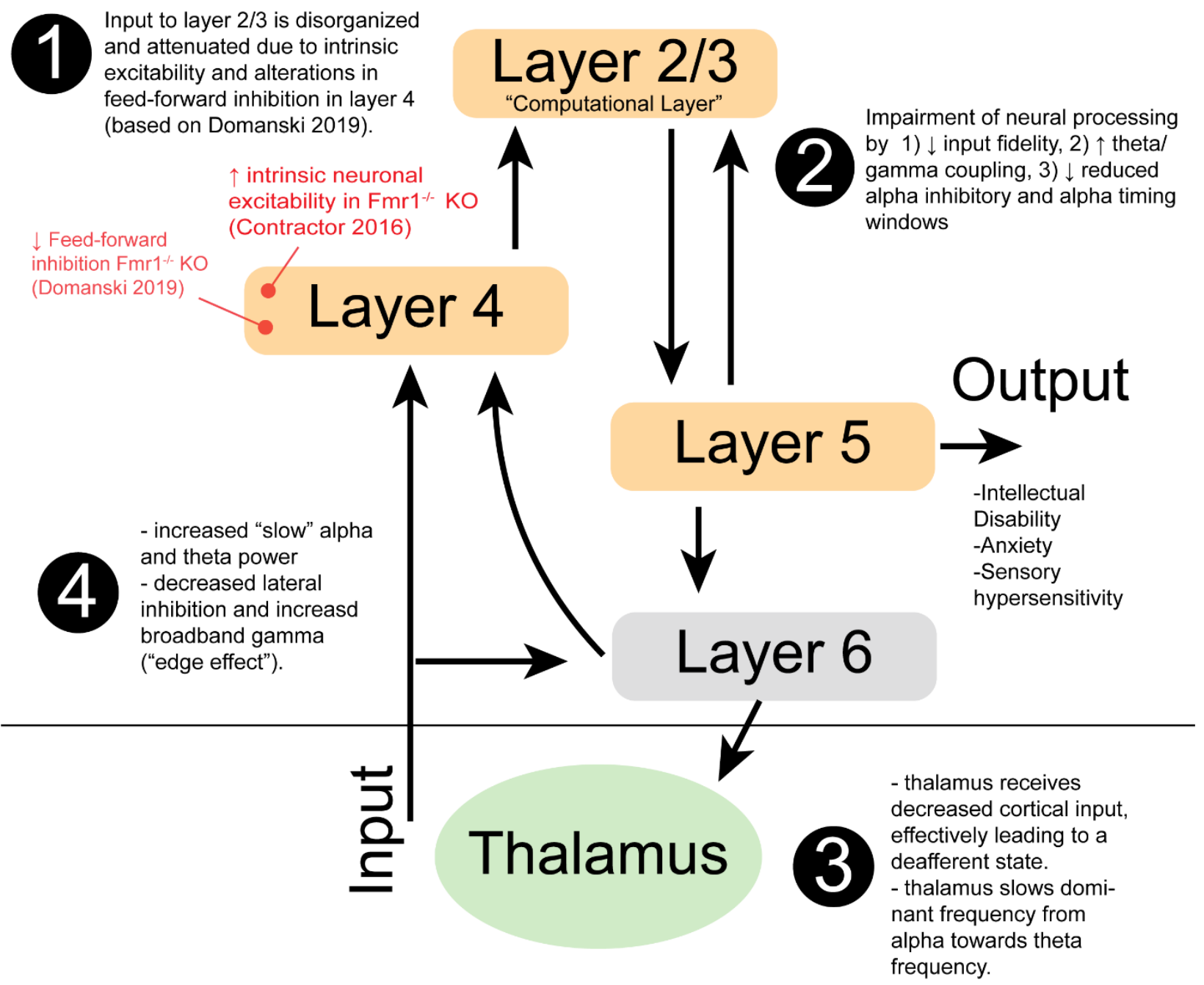

Figure 4: Hypothetical model of thalamocortical dysrhythmia (TCD) in FXS patients. In several neuropsychiatric conditions, pathological slowing of alpha oscillations is observed across M/EEG and intraoperative LFP recordings. 1) Recent study of thalamocortical circuits in $\mathrm{Fmr}^{-/-}$ $\mathrm{KO}$ mice observed an attenuation of complex sensory input to neocortex (layers 2/3). 2) Diminished input with other pathological changes may lead to impaired cognitive processes, 3 ) Thalamic feedback is effectively reduced. In the deafferent state, the dominant alpha frequency $(8-13 \mathrm{~Hz})$ of the thalamus is reduced to theta frequency range $(5-7 \mathrm{~Hz}) .4)$ consequences of reduced alpha power result in additional broadband gamma, inefficient dependence on theta activity and reduced SNR of information processing. (Red, relevant $\mathrm{Fmr}^{-1-} \mathrm{KO}$ evidence) 
Table 1: Demographic and clinical features of the EEG dataset showing mean $( \pm$ standard deviation) group t-tests. FSIQ, Full Scale IQ; NVIQ, Non-verbal intelligence quotient; VIQ, verbal intelligence scale; SCQ, Social Communication Questionnaire; WJ-3, Woodcock III Tests of Cognitive Abilities; adj. p, p-value following Bonferroni correction.

\begin{tabular}{llllll}
\hline Measure & FXS $(n=70)$ & Control $(n=71)$ & $t$ & $p$ & adj. $p$. \\
\hline Age (years) & $20.5+/-10$ & $22.2+/-10.7$ & -0.94 & 0.350 & 0.700 \\
Sex & F: 32 M: 38 & F: $30 \mathrm{M}: 41$ & 0.17 & 0.740 & 0.740 \\
FSIQ & $49.5+/-30.2$ & $103.2+/-9.2$ & -12.59 & $<.001$ & $<.001$ \\
NVIQ & $40+/-35.7$ & $103.4+/-10.7$ & -12.56 & $<.001$ & $<.001$ \\
VIQ & $58.9+/-28.7$ & $103.1+/-12.8$ & -10.45 & $<.001$ & $<.001$ \\
SCQ & $13.6+/-7.7$ & $2.1+/-2.2$ & 9.94 & $<.001$ & $<.001$ \\
WJ3 & $67.8+/-15.7$ & $94.1+/-12.1$ & -8.10 & $<.001$ & $<.001$ \\
\hline
\end{tabular}


medRxiv preprint doi: https://doi.org/10.1101/2021.05.12.21256925; this version posted May 13, 2021. The copyright holder for this preprint (which was not certified by peer review) is the author/funder, who has granted medRxiv a license to display the preprint in perpetuity.

Table 2: Group differences in cortical atlas node relative log power by frequency band. Estimates (Est.) reflect FXS-control with values greater than one indicating FXS greater than control. FDR, false discovery rate; L, Left; R, Right; C, Central; L, Lingula; P, Parietal; T, Temporal; t, t-value; PF, prefrontal; MNI, Montreal Neurological Institute X, Y, $Z$ coordinates of ROI centroid; STS, superior temporal sulcus.

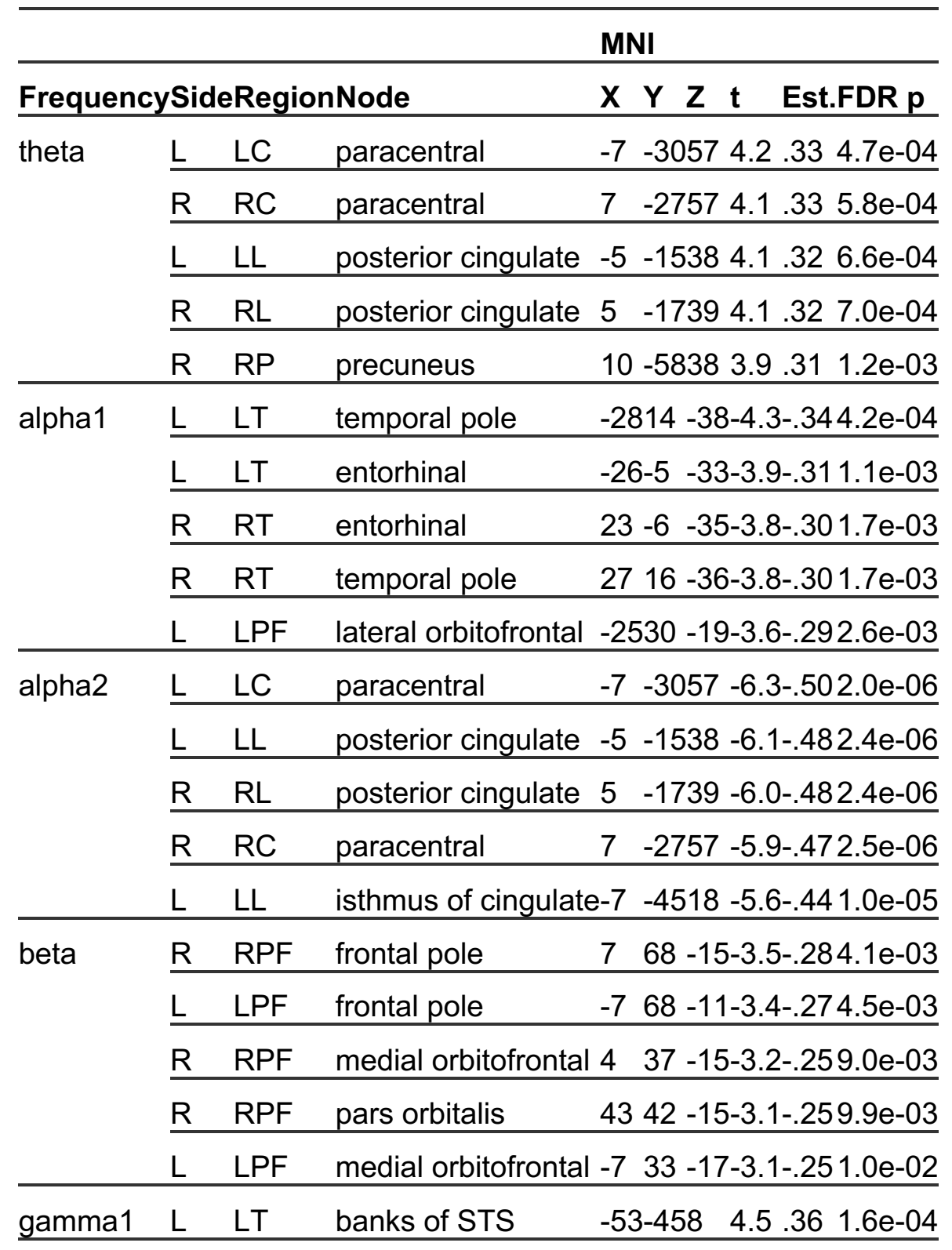




\begin{tabular}{|c|c|c|c|c|c|}
\hline \multicolumn{6}{|c|}{ MNI } \\
\hline \multicolumn{6}{|c|}{ FrequencySideRegionNode } \\
\hline & $\underline{\mathrm{R}}$ & $\mathrm{RT}$ & transverse temporal46 -179 & 4.2 & $.335 .4 \mathrm{e}-04$ \\
\hline & $\mathrm{R}$ & $\mathrm{RL}$ & isthmus of cingulate $6 \quad-4219$ & 3.3 & $.266 .4 \mathrm{e}-03$ \\
\hline & $\underline{\mathrm{L}}$ & LP & supramarginal & 3.3 & 3.26 6.5e-03 \\
\hline & $\mathrm{L}$ & $\mathrm{LT}$ & transverse temporal-46-2310 & 3.2 & $.258 .2 \mathrm{e}-03$ \\
\hline \multirow[t]{5}{*}{ gamma2 } & $\underline{\mathrm{L}}$ & $\mathrm{LT}$ & banks of STS & & $.353 .0 \mathrm{e}-04$ \\
\hline & $\underline{R}$ & RT & transverse temporal46 -179 & & $3.301 .5 \mathrm{e}-03$ \\
\hline & $\underline{L}$ & $\mathrm{LT}$ & transverse temporal-46-2310 & 3.4 & $.274 .8 e-03$ \\
\hline & $\underline{\underline{L}}$ & LP & supramarginal & 3.2 & $.267 .9 \mathrm{e}-03$ \\
\hline & $\mathrm{R}$ & RT & banks of STS & 3.1 & $.241 .1 \mathrm{e}-02$ \\
\hline
\end{tabular}


Table 3: Sex and group effect on regional log-transformed relative power (mean differences \pm standard deviation) by frequency band. Total number of significant regions out of total regions (central, frontal, occipital, parietal, and temporal) denoted in parentheses. FXS, Fragile X Syndrome; TDC, Typically Developing Controls.

\begin{tabular}{lllll}
\hline & \multicolumn{2}{l}{ Male-Female (Matched Group) } & \multicolumn{2}{l}{ FXS-Control (Matched Sex) } \\
\hline Frequency & FXS(M)-FXS(F) & TDC(M)-TDC(F) & FXS(F)-TDC(F) & FXS(M)-TDC(M) \\
\hline Delta & n.s. & n.s. & n.s. & $+.12(1 / 5)$ \\
\hline Theta & n.s. & n.s. & $+.16 \pm .01(4 / 5)$ & $+.26 \pm .10(5 / 5)$ \\
\hline Alpha1 & $-.19 \pm .02(2 / 5)$ & $+.15(1 / 5)$ & $-.16 \pm .03(2 / 5)$ & $-.26 \pm .03(5 / 5)$ \\
\hline Alpha2 & $-.20 \pm .05(4 / 5)$ & $+.15(1 / 5)$ & $-.23 \pm .04(5 / 5)$ & $-.45 \pm .11(5 / 5)$ \\
\hline Beta & $+.18 \pm .06(5 / 5)$ & $-.12(1 / 5)$ & $-.21 \pm .06(5 / 5)$ & n.s. \\
Gamma1 & $+.38 \pm .08(5 / 5)$ & $-.01 \pm .35(2 / 5)$ & $-.20 \pm .11(3 / 5)$ & $+.27 \pm .08(5 / 5)$ \\
\hline Gamma2 & $+.40 \pm .06(5 / 5)$ & $-.10 \pm .23(4 / 5)$ & $-.27 \pm .12(4 / 5)$ & $+.30 \pm .08(4 / 5)$ \\
\hline
\end{tabular}




\section{(A) Overview of methodology}

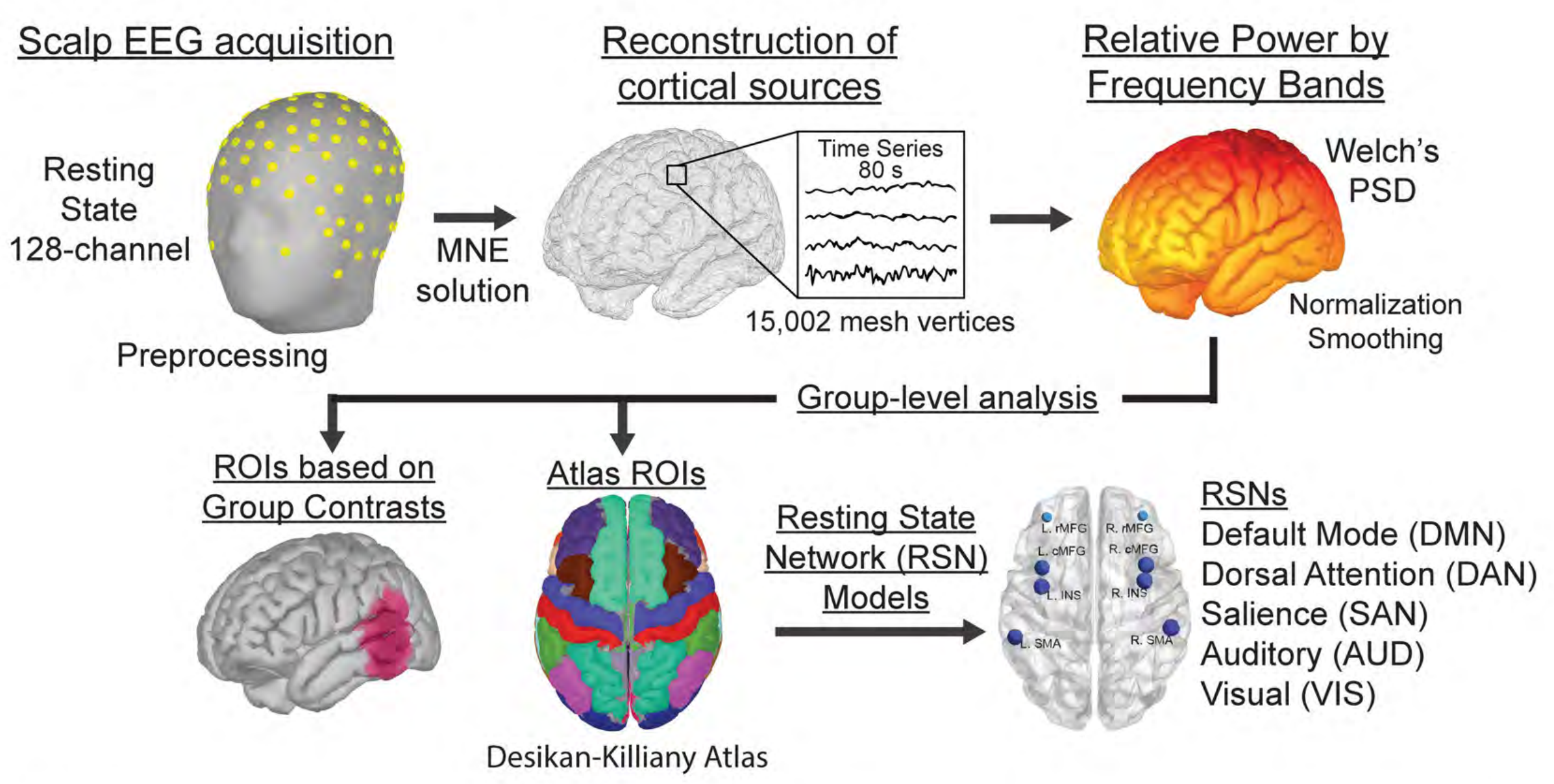

(B) Intellectual disability by group and sex

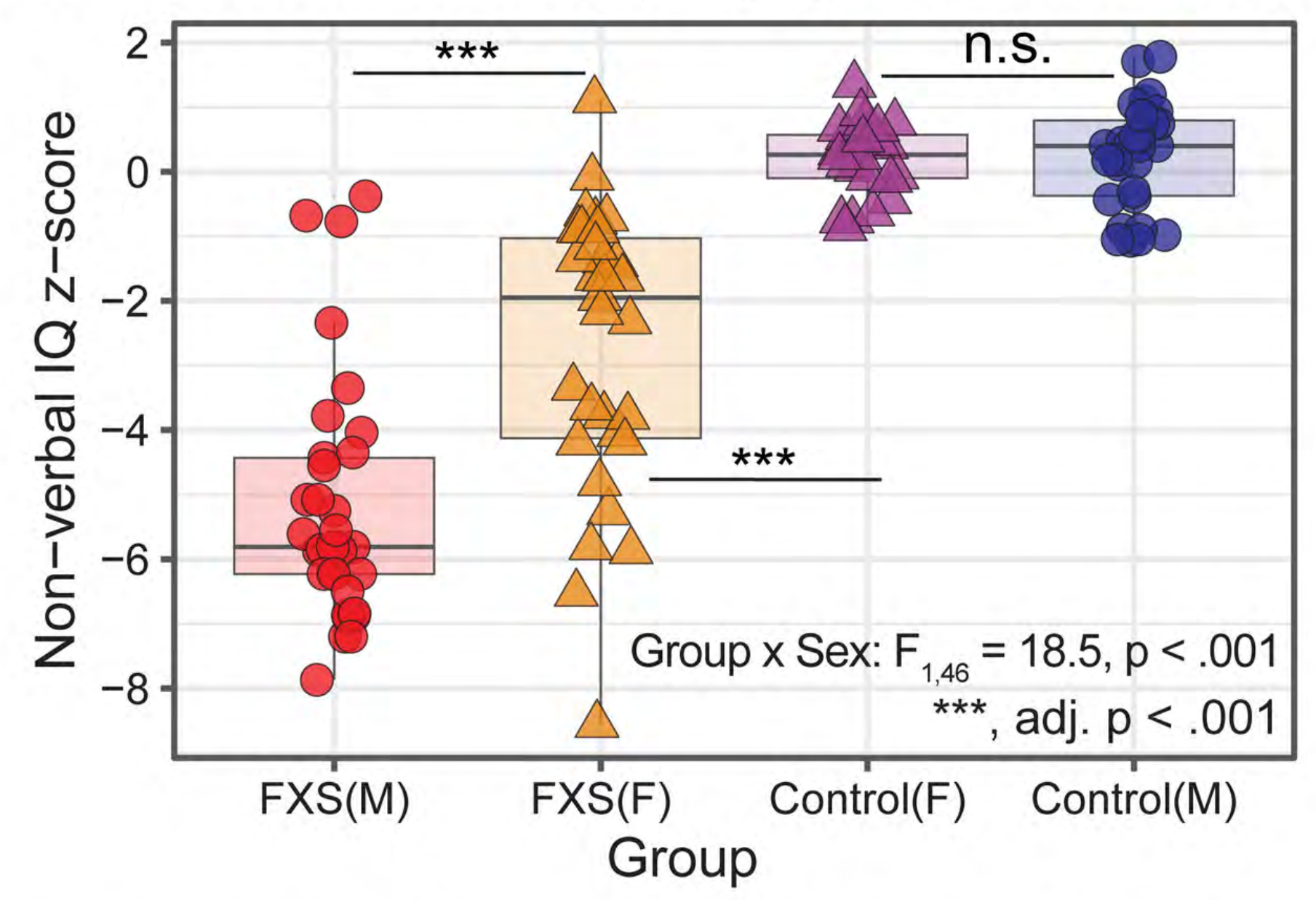

(C) Spectrogram of Scalp EEG Relative Power (D) Cortical source estimates of power contrasts (FXS-Con-

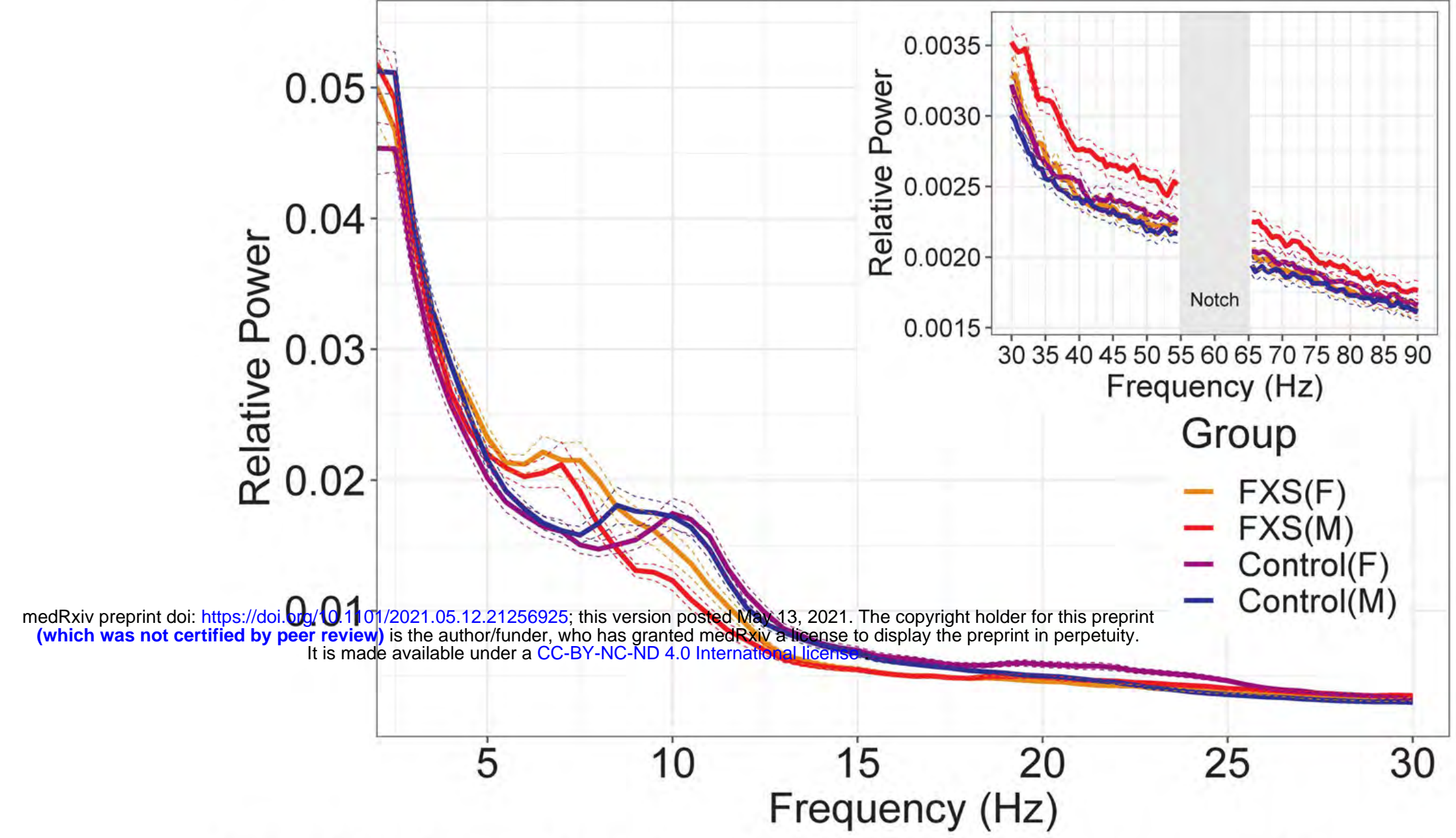

(E) Subject distribution of sig. power differenc-

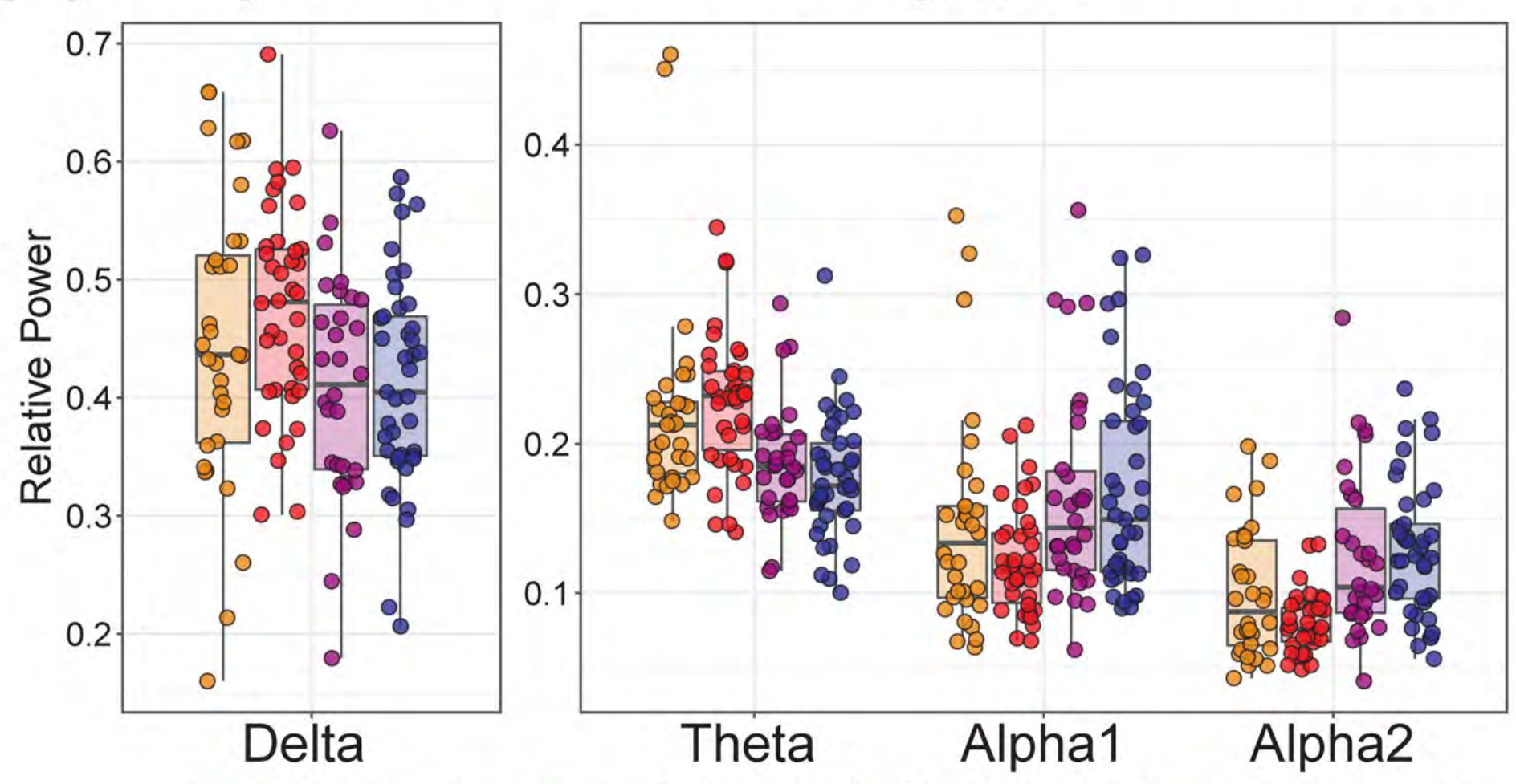

FXS (female) FXS (male) TDC (female) TDC (male)

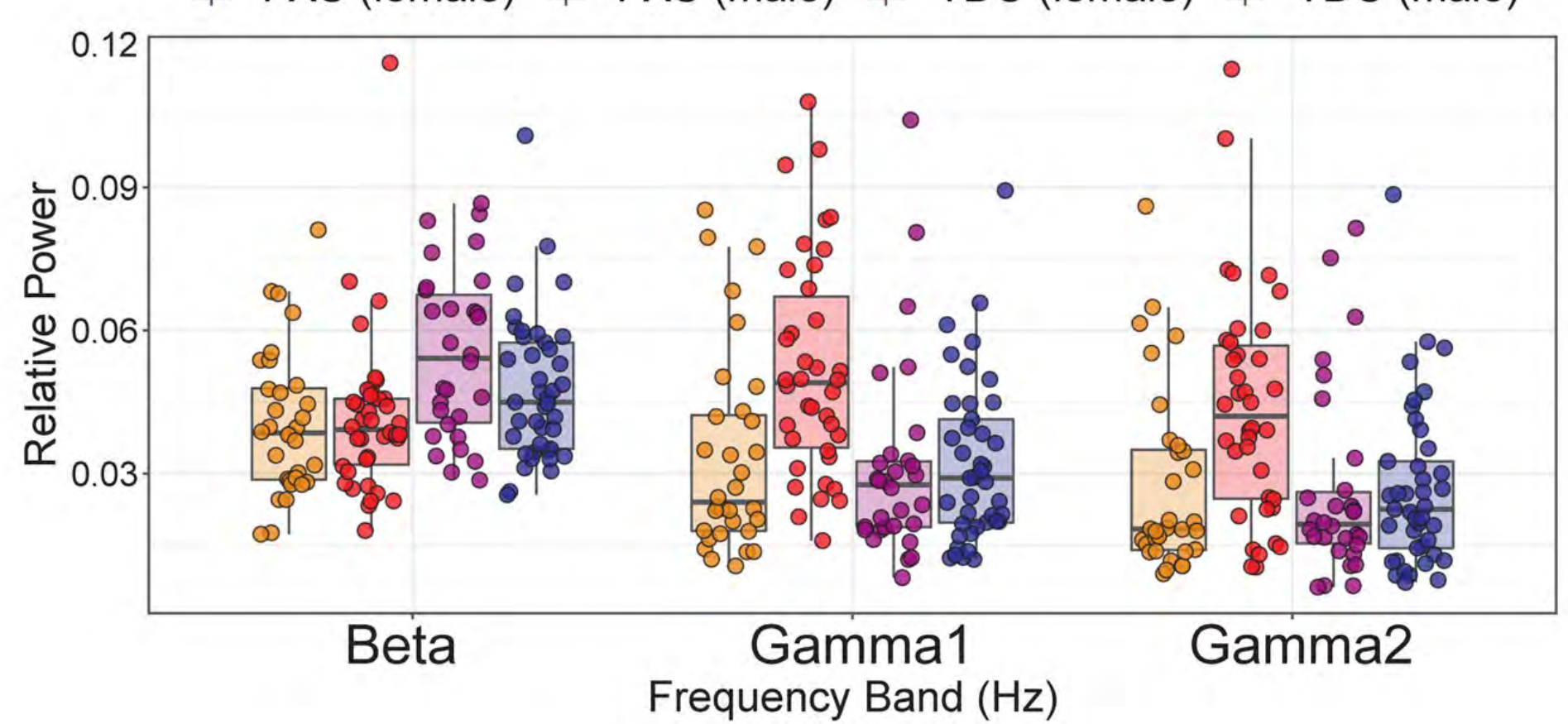

Delta

2-3.5 Hz

Theta

4-7.5 Hz

Alpha1

8-10 Hz

Alpha2 10.5-

$12.5 \mathrm{~Hz}$

Beta

13-30 Hz

Gamma1 $30-55 \mathrm{~Hz}$

Gamma2 $65-90 \mathrm{~Hz}$
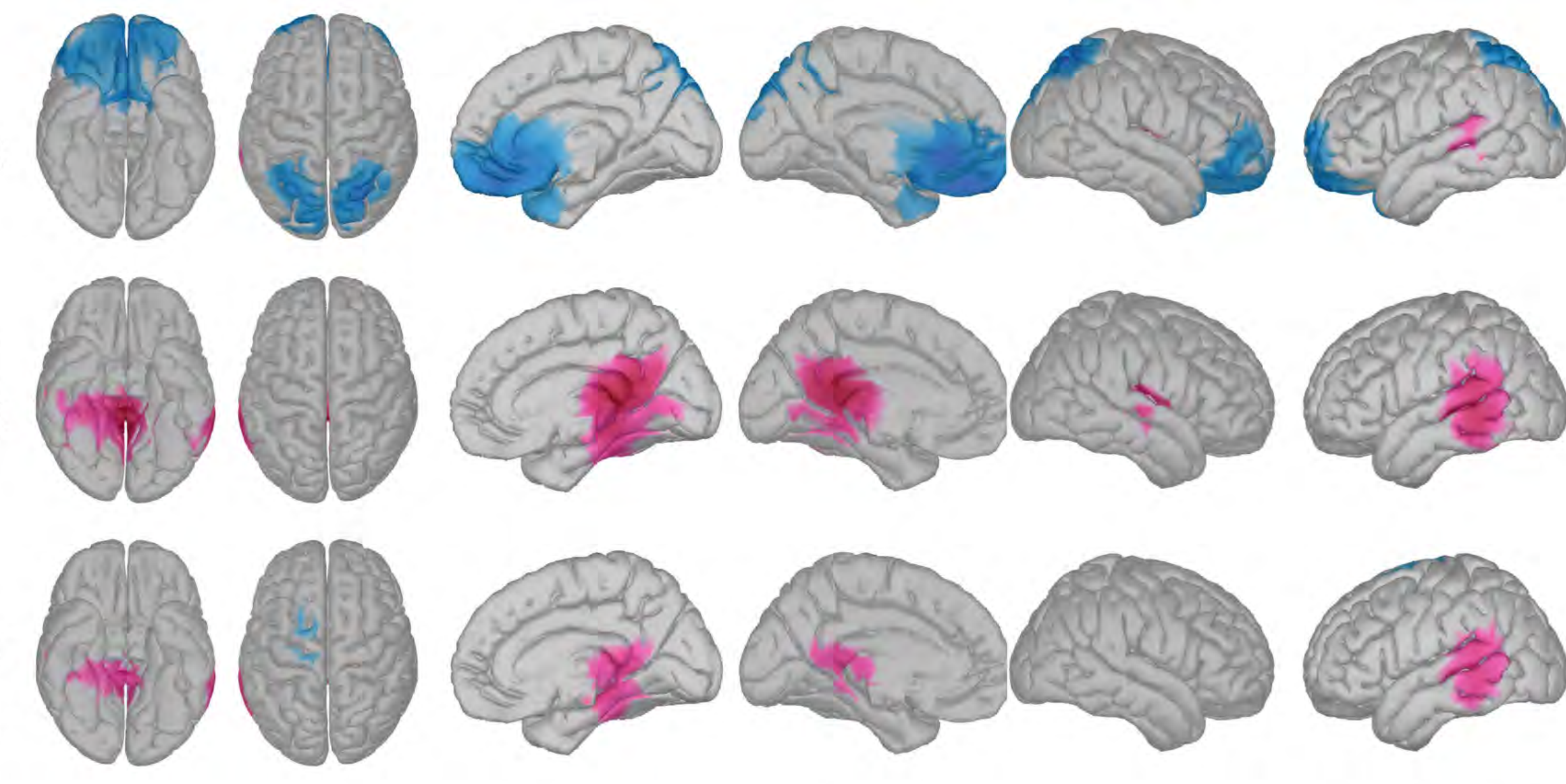

Superior

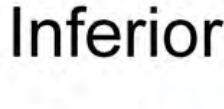

L. Lateral

R. Lateral

L. Sagittal

R. Sagittal

5 Cooler colors indicated FXS $<$ TDC t-value Warmer colors indicate FXS > TDC 
(A) Lower peak frequency in FXS across default mode network (DMN)

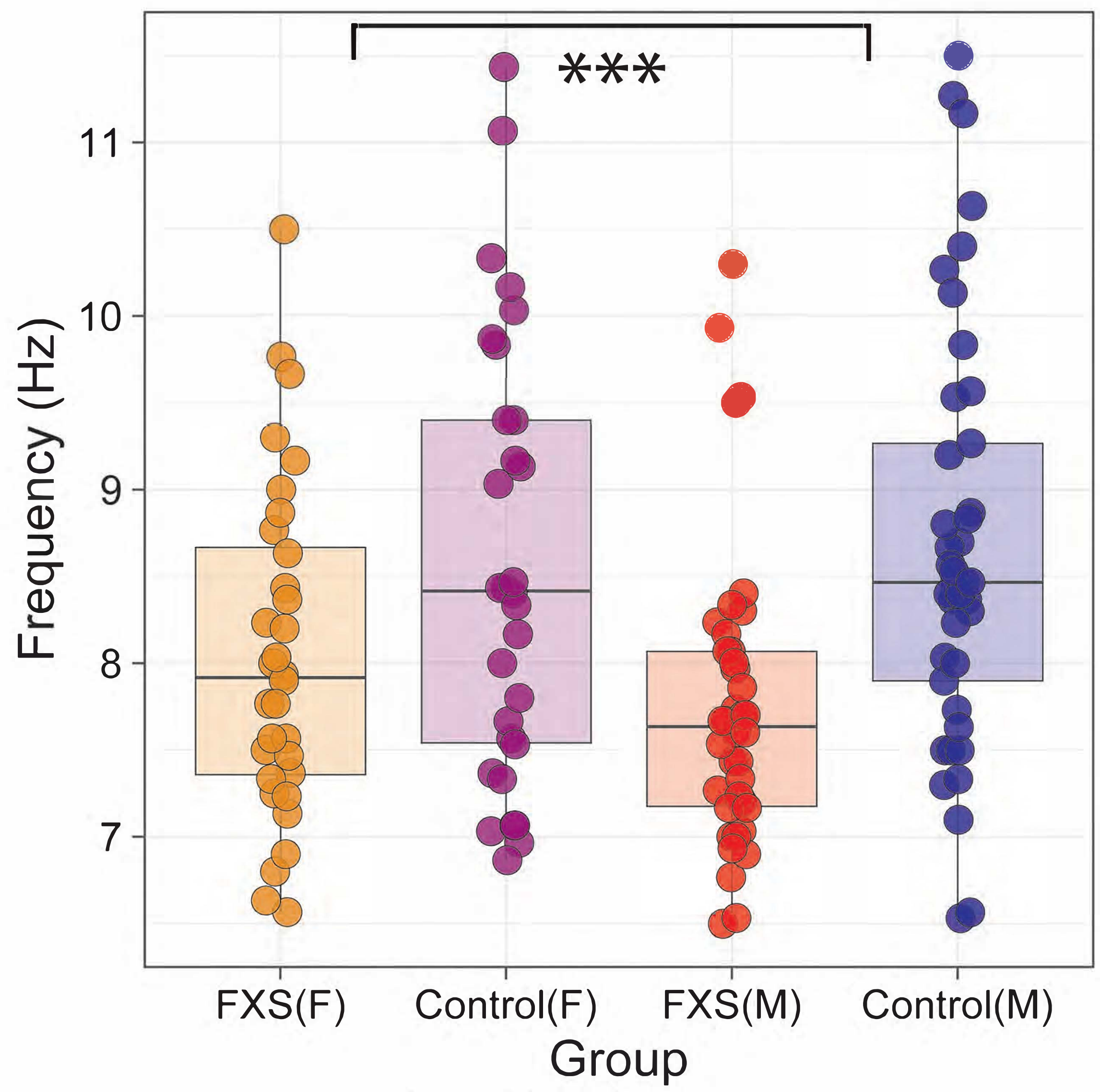

(B) Inverted alpha vs. theta with gamma1 amplitude coupling of DMN in FXS
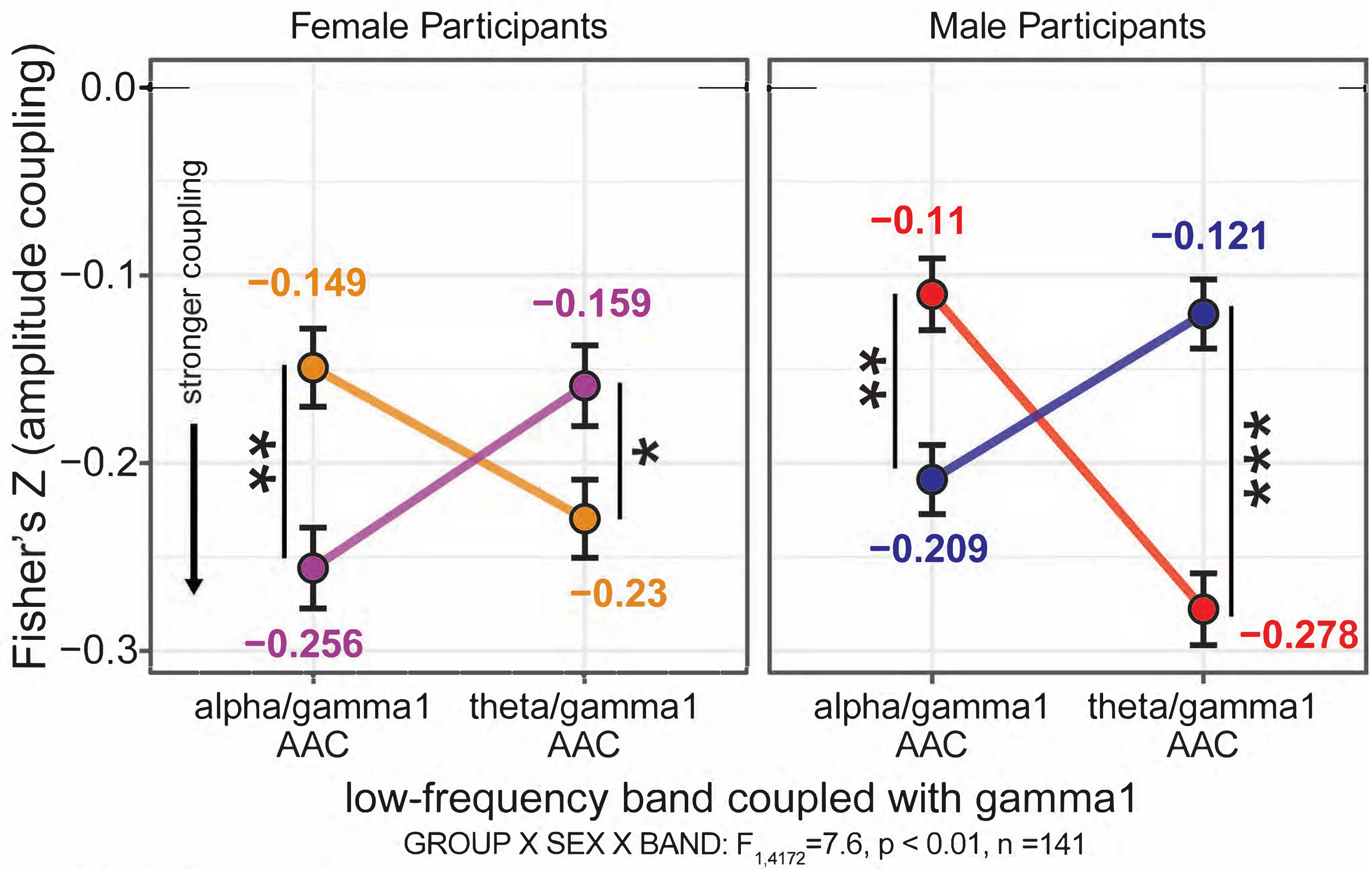

OFXS (F) OFXS (M)

OControl (F) Control (M)
n.s., non-significant $\quad *$, adj. $p<.05$
$*$, adj. $p<.001 \quad$ * adj. $p<1 \times 10^{-4}$

(C) Alpha power is slowed and anteriorly distributed in FXS patients (paired subject data)

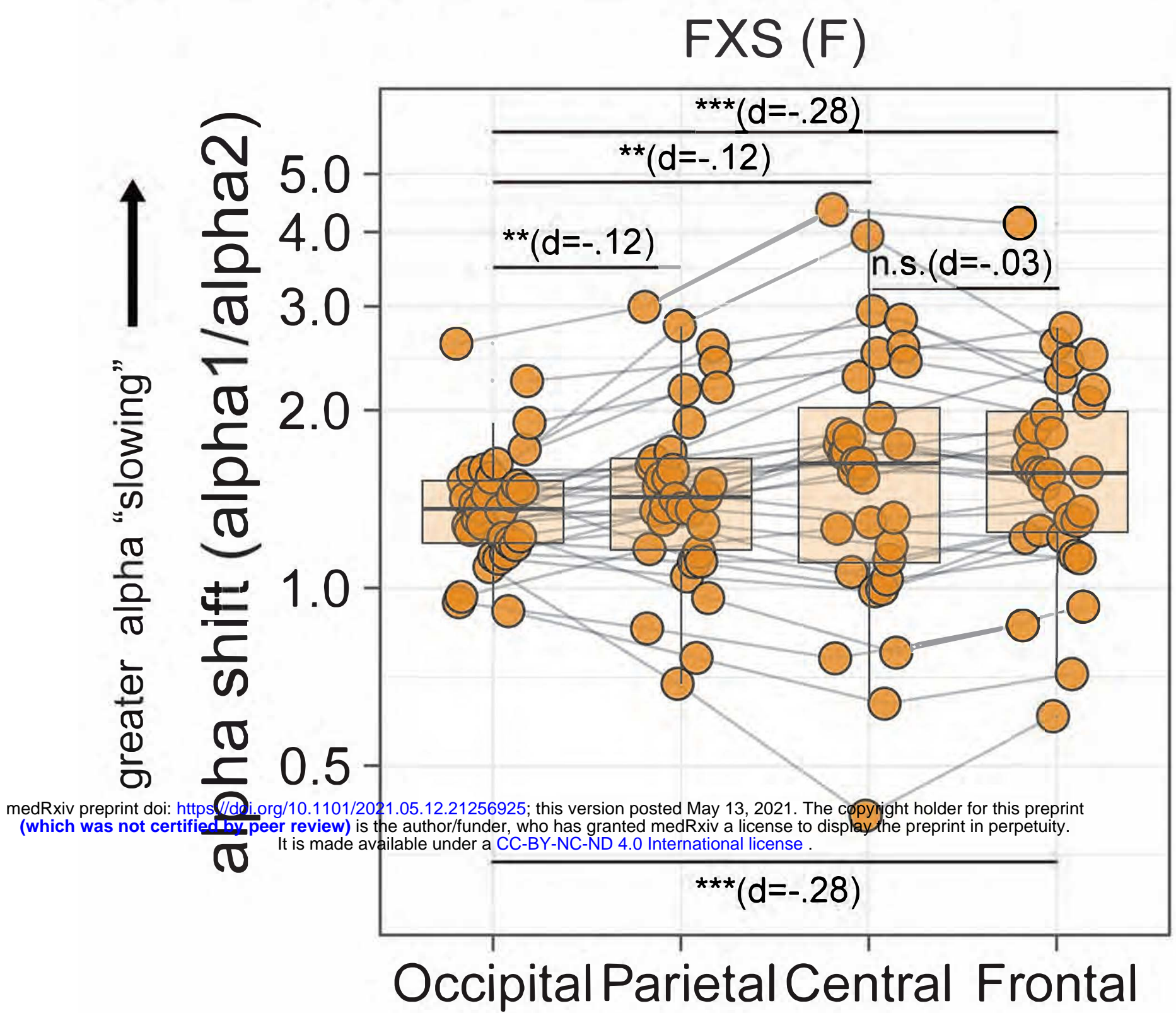

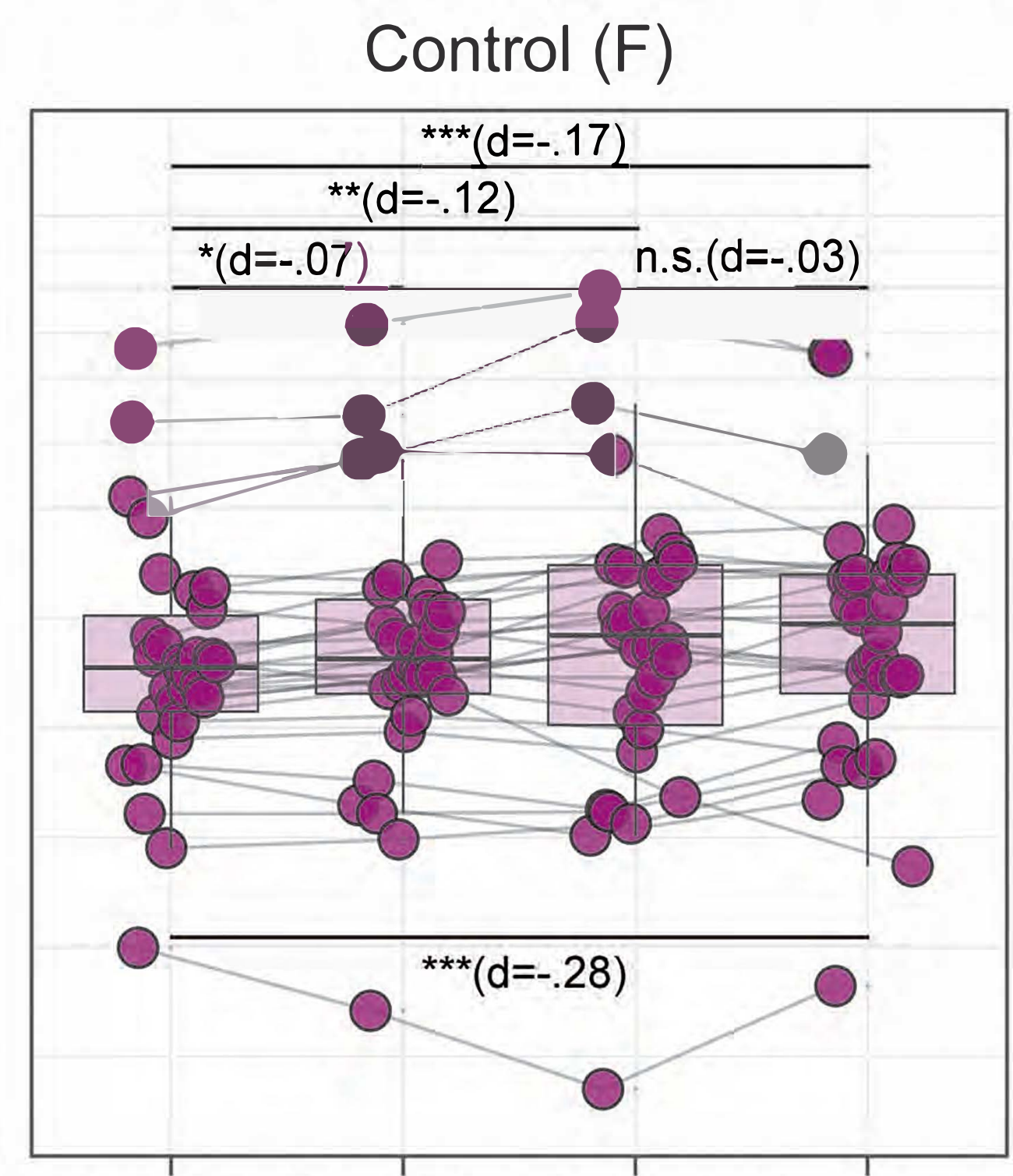

Occipital Parietal Central Frontal

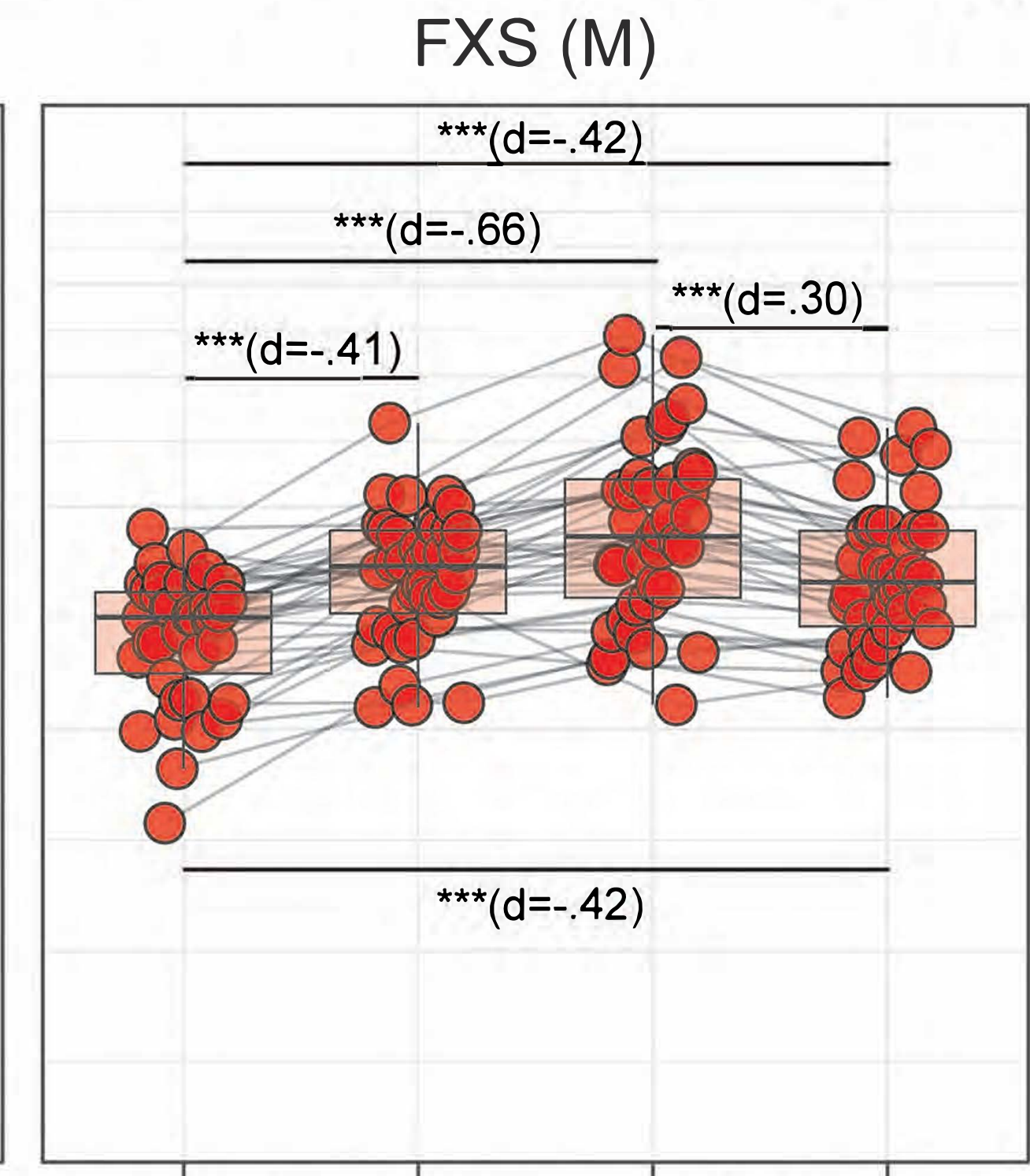

Occipital ParietalCentral Frontal

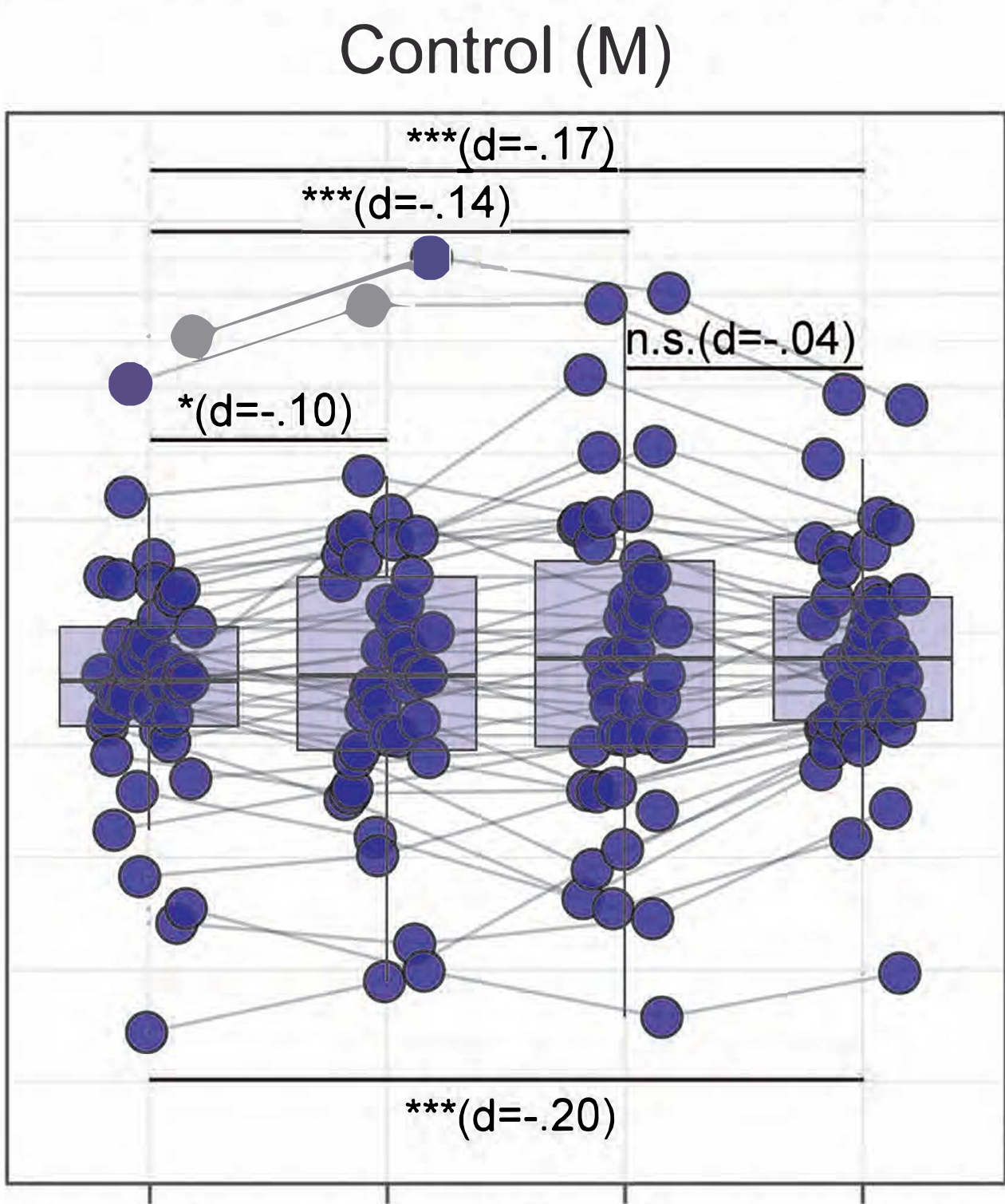

Occipital Parietal Central Frontal Cortex Region (Posterior to Anterior)

(D) Signficant alpha-rhythm slowing and anterior spread in male patients with FXS

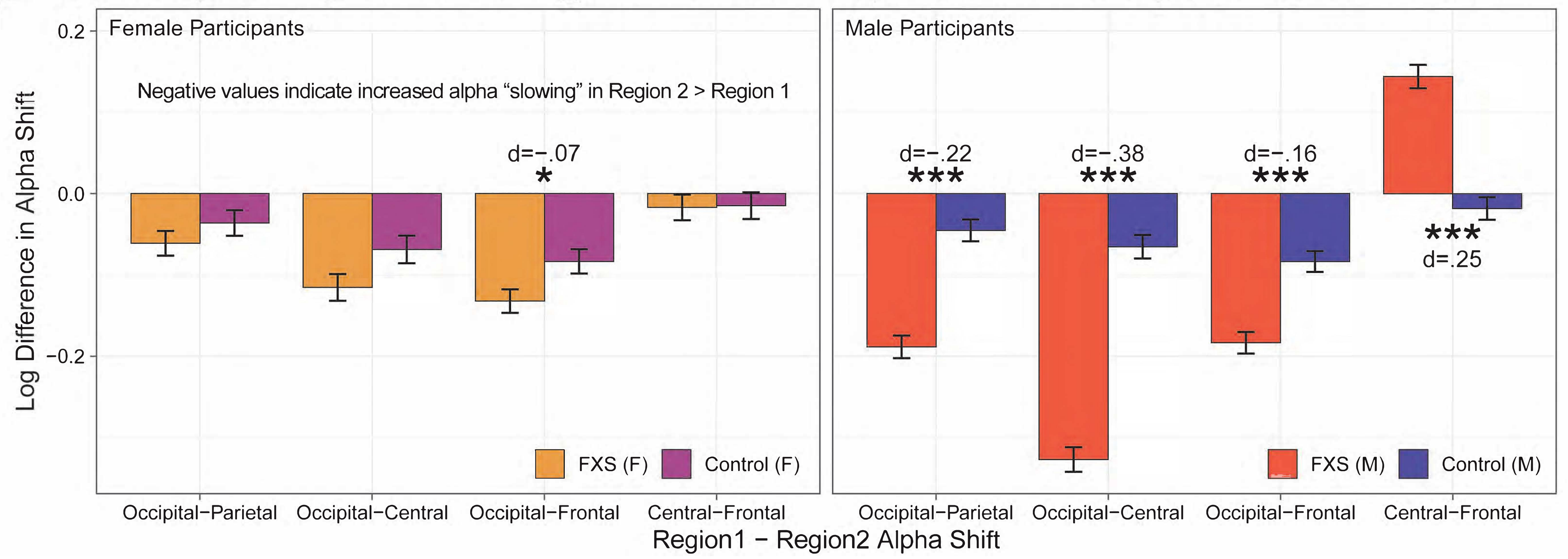


(A) Relative power differences (FXS - Control) within default mode network (DMN)
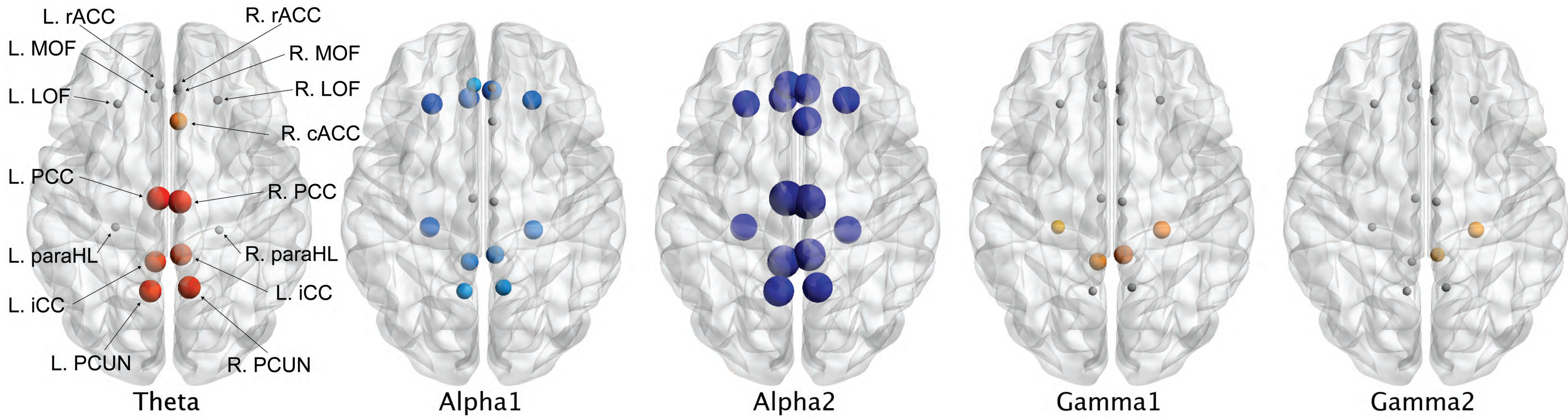

FDR corrected $-6 \frac{\text { t-value }}{\text { n.s. }} 6$ Cooler colors: FXS < Control Warmer colors: FXS > Control

(B) Resting state networks (RSN) in relative power differences (FXS - TDC) by sex FXS Male - Control Male



FXS Male - FXS Female

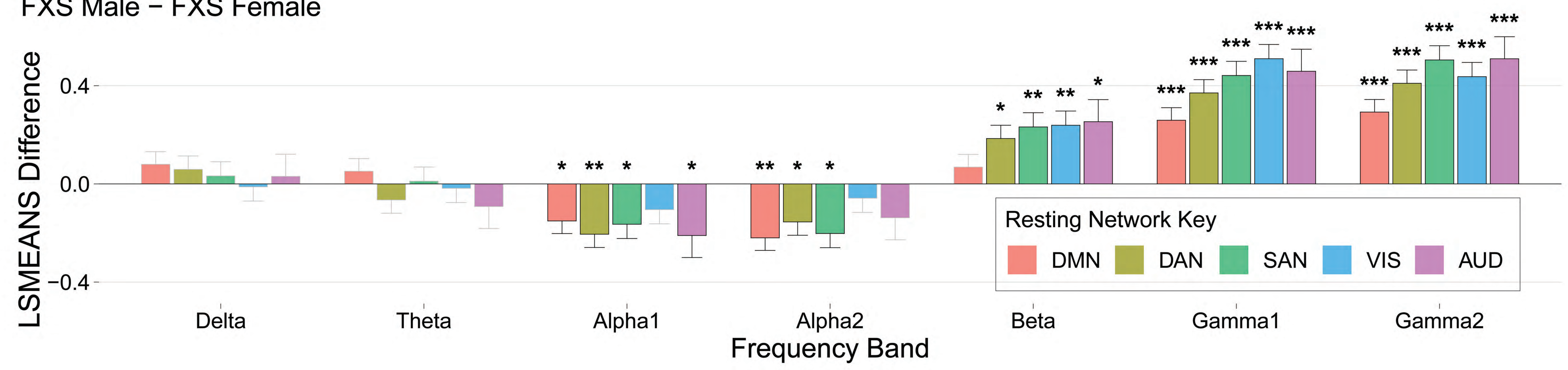

(C) Correlation of intellectual disability in FXS with mean DMN Gamma Power

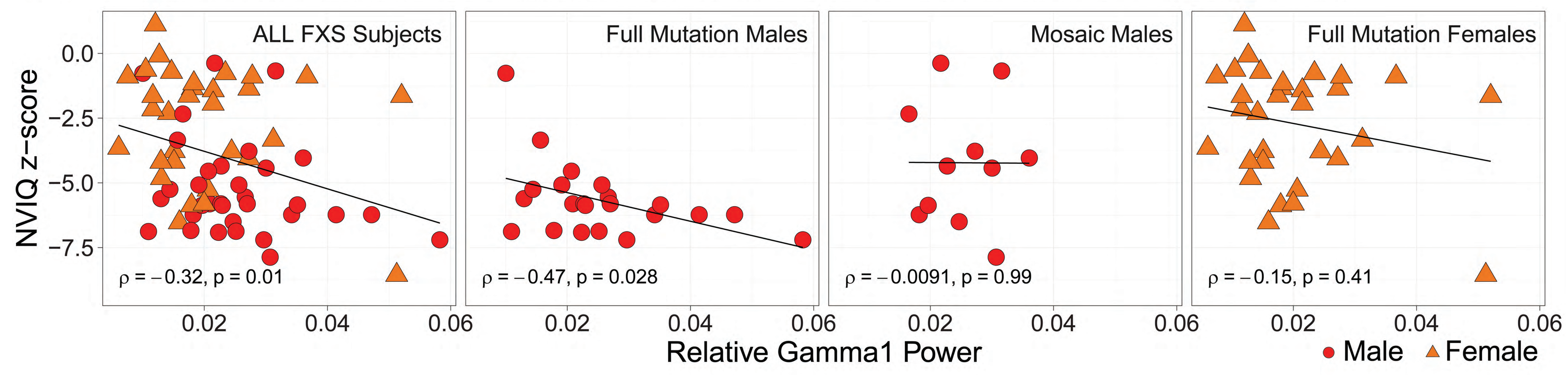

(D) Correlation of Anxiety in FXS with mean VIS Alpha2 Power

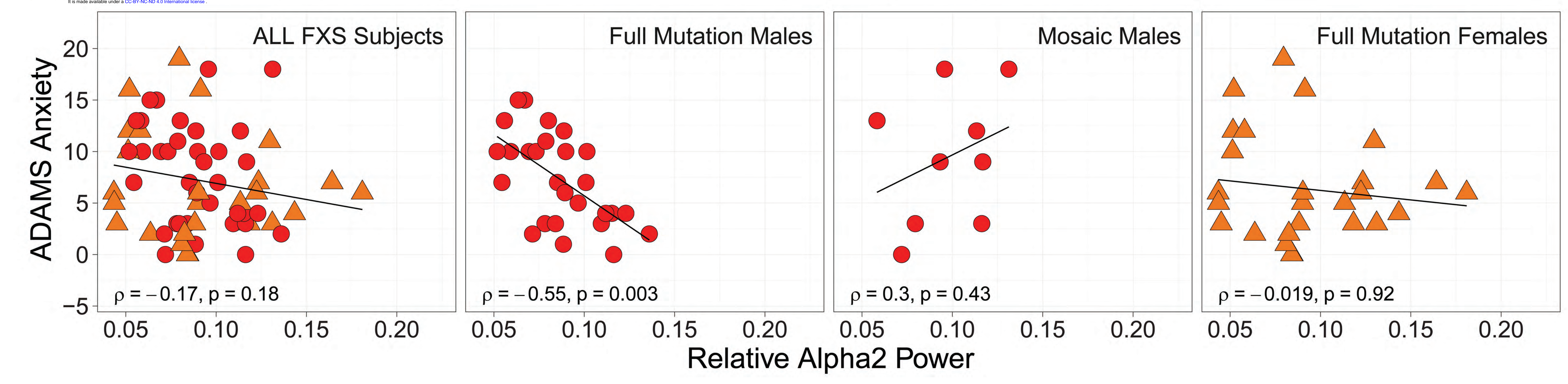




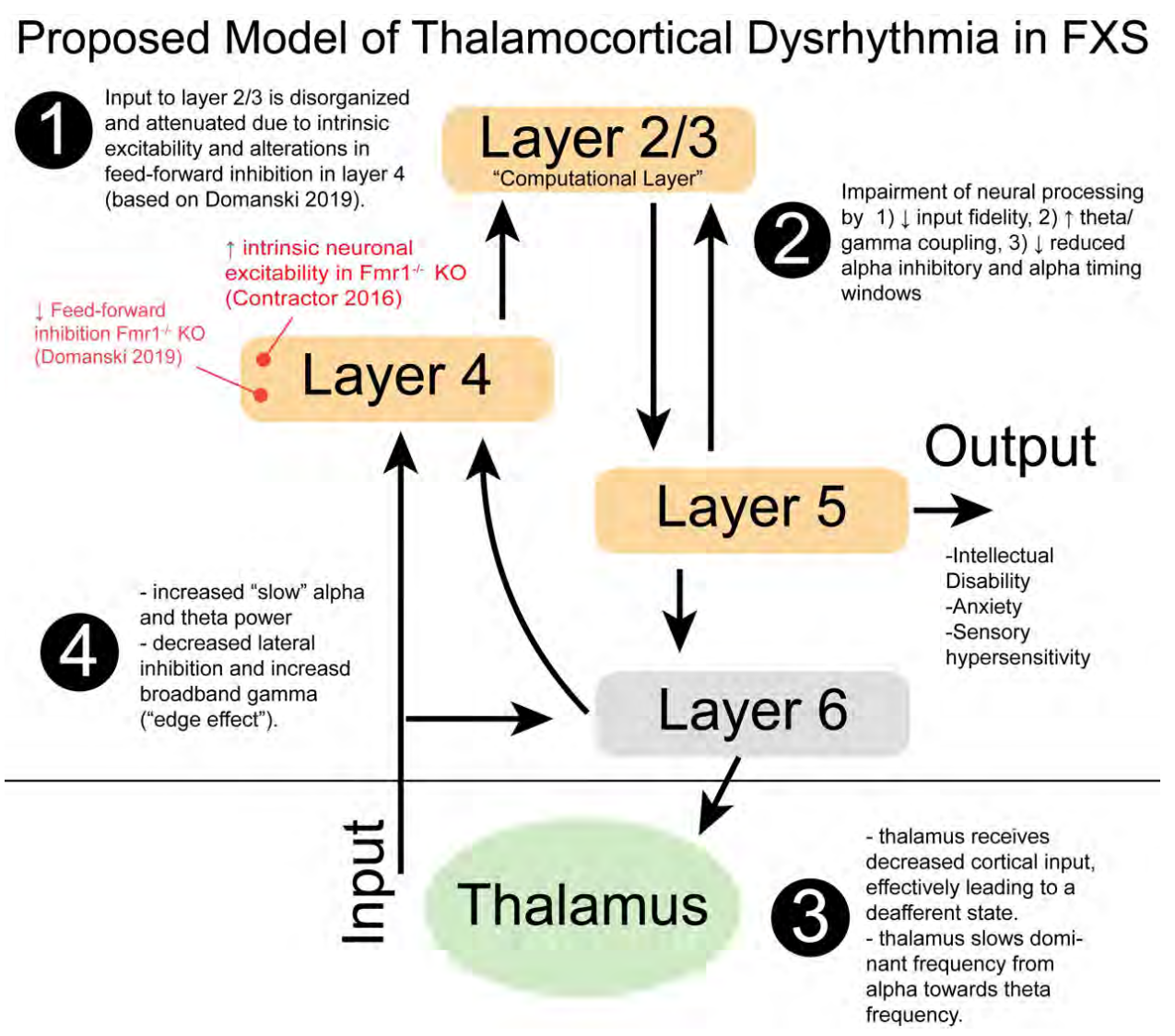

